\title{
The Chronometric Dating and Subsistence of Late Neanderthals and Early Anatomically Modern Humans in the Central Balkans Insights from Šalitrena Pećina (Mionica, Serbia)
}

\author{
ANA B. MARÍN-ARROYO, Instituto Internacional de Investigaciones Prehistóricas de \\ Cantabria, Universidad de Cantabria, Avda. de los Castros, s/n, 39005 Santander, Spain, \\ and Leverhulme Centre for Evolutionary Studies. Dpt. of Archaeology and Anthropology. University \\ of Cambridge.Cambridge, United Kingdom.Email: marinab@unican.es \\ B OJANA MIHAILOVIĆ, Department of Archaeology. National Museum of Belgrade, \\ Republic Square 1a, 11000 Belgrade, Republic of Serbia
}

Eastern Europe, particularly the Balkans, played a major role as a likely cul-de-sac for late $\mathrm{Ne}$ anderthal survival and as a gateway to Europe for Anatomically Modern Humans (AMH) during the Middle to Upper Paleolithic transition. Despite the importance of the region, the known archaeological record during this period is still very limited, with little available site information. The recently excavated site of Šalitrena Pećina (Mionica, Serbia), south of the Danube River, contains archaeological evidence of late Mousterian, Aurignacian, and Gravettian occupations and presents an opportunity for understanding the behavior of both human populations in this eastern European region. Here we present the first radiocarbon dates for Neanderthal and AMH occupations in Serbia, as well as preliminary evidence on subsistence strategies obtained from the Mousterian and Aurignacian macrofaunal assemblages in Šalitrena Pećina. Radiocarbon dates indicate that Neanderthal and AMH groups may not have coexisted and interacted in this site. Nevertheless, zooarchaeological and taphonomic results show that both human populations were the main depositional agents of macrofaunal accumulation at the cave. The general compositions of the faunal assemblages reflect subtle differences between both human types and point to the necessity of further multidisciplinary research in southeastern Europe to increase our knowledge about human behavior and the causes of the demise of the Neanderthals in the Balkans.

Key words: Neanderthals, Anatomically Modern Humans, Subsistence, Šalitrena Pećina, Serbia, dates

The Middle to Upper Paleolithic transition in Europe is a key period in human evolution directly linked to late Neanderthal and early Anatomically Modern Human $(\mathrm{AMH})$ populations. The Neanderthal extinction is recognized as a regionally diverse 
phenomenon rather than a uniform pan-European event. The reasons behind their demise and the survival of AMH are still unknown and hotly debated. Current prevailing hypotheses are diverse and inconclusive, deriving from the study of the archaeological record from different theoretical perspectives. Existing theories include: dietary differences between the two types of hominins (Bocherens and Drucker 2006; Hockett and Haws 2003; Richards and Trinkaus 2009), Neanderthal technological inefficiency (Pettitt 1999; Shea and Sisk 2010), demographic imbalances (Flores 1998; Mellars and French 2011; Zubrow 1989), environmental shifts (Finlayson 2004; Stewart 2004), competition with modern humans (Banks et al. 2008), decline in genetic diversity (Green et al. 2010), and cognitive differences (Mellars 1991; Soffer 1994), among others (see Villa and Roebroeks 2014 for an update of the debate).

Neanderthals and AMH were contemporaneous in various regions of Eurasia for several millennia. However, Neanderthals failed to survive, disappearing within no more than ca. 5,000 years of their first encounters with AMH (Higham et al. 2014). Methodological advances in radiocarbon dating (Bronk Ramsey et al. 2004; Higham et al. 2006a) have removed young carbon contamination from old organic samples up to the limit of the method at $-50,000$ years ago, a crucial time when the transition between the two human species took place, allowing for a more precise temporal identification of the replacement than was previously possible. Now, even the very existence of southwestern (i.e., Iberian) refugia for Neanderthal populations toward the end of Marine Isotope Stage 3 (MIS3 - 57-27 ka) (Higham et al. 2014; Wood et al. 2013) has been challenged.

Modern humans rapidly colonized Europe, from the Near East to Iberia, with the earliest Aurignacian cultural evidence identified at $-47-45 \mathrm{ka}$ (GI-12) (Müller et al. 2011). Although the taxonomic status of the makers of these earliest phases of the Upper Paleolithic is poorly documented, AMH expansion has been traced through the so-called Initial Upper Paleolithic (IUP; i.e., Protoaurignacian and Aurignacian complexes) and some "transitional" technological industries (Uluzzian, LincombianRanisian-Jerzmanowician [LRJ], Szeletian, and Châtelperronian in various regions of Europe). These industries suggest cultural contacts between local and immigrant populations and presage the onset of the Upper Paleolithic in western and central Europe (Hublin 2015).

The dispersal of Proto-Aurignacian and Aurignacian technologies likely shows a rapid advance of AMH along two main routes: up the Danube Valley (Conard 2002; Mihailović et al. 2011; van Andel et al. 2003) and along the Mediterranean coast (Mellars 2011). This relatively fast migration may have coincided with the displacement of Neanderthal populations toward more patchy and previously unexploited regions either because of direct and unsuccessful competition with modern humans (Stewart 2004) or because they failed to adapt to unsuitable MIS3 environmental conditions and climatic instability (Finlayson 2009; Stewart 2007), despite their previous success at surviving climatic crises. 
In spite of the fact that the Balkan region has long been considered a likely gateway to Europe for AMH (Conard and Bolus 2003; Kozlowski 1998, 2006; Mihailović et al. 2011; Roebroeks 2008), very few sites dated to the Middle to Upper Paleolithic transition have been found, particularly in Serbia (see Mihailović, ed. 2014 and Mihailović et al. 2011 for an updated synthesis for the Central Balkans). Possible reasons for this include the political upheavals of the 1990s, the lack of systematic archaeological surveys, and a very limited Paleolithic research history in this area (Mihailović et al. 2011). To date, no Aurignacian sites have been found in the mountainous zone between Croatia and Bulgaria, and only a few Mousterian sites have been recorded in Serbia (Smolucka Pećina, Malisina Stijena, Hadzi Prodanova Pećina and Tabula Traiana) and Montenegro (Crvena Stijena: Basler 1975; Morley and Woodward 2011). None of these provide information about diet and subsistence, either because of the lack of preserved bone or because, when bones are preserved, they can be attributed to carnivore (mainly hyena) accumulations (Mihailović and Mihailović 2009). The available information about fossil mammal assemblages of the Upper Pleistocene consists of paleontological studies that only indicate the relative abundance of each species and general ecological considerations (Dimitrijević 1997). Only in recent years have faunal accumulations begun to be investigated from an archaeozoological point of view (Dimitrijević et al. 2014).

To date, the only Paleolithic human bone found in Serbia is a mandible (BH-1) from Mala Balanica with primitive characteristics comparable to Early Pleistocene mandibular specimens, associated with a minimum radiometric date of 113,000 +72,000/ $-43,000$ years ago (dated by U/Th series). It does not appear to exhibit any derived Neanderthal traits (Roksandic et al. 2011).

Recent excavations offer, for the first time, an outstanding opportunity to explore a territory that lies between the two proposed routes of colonization of Europe by AMH. Much of Serbia is characterized by mountainous landscape and, despite being crossed by secondary fluvial valleys, is somewhat isolated. Although Europe in the second half of MIS3 was climatically unstable, the Balkans might have served as a refugium for plant and animal species due to the favorable conditions present, especially in the west of the peninsula, where the humidity was higher (Griffiths et al. 2004; Tzedakis 2004; Tzedakis and Bennett 1996; Weiss and Ferrand 2007). As a result, Neanderthal populations inhabiting the region may have escaped the negative influences of climatic change that provoked shifts in ecological zones between the northwest and the southeast of Europe (Dogandžić et al. 2014; Mihailović 2009; Mihailović et al. 2011).

Šalitrena Pećina, located southwest of the Danube River in central Serbia, has been the subject of ongoing excavation since 2004. This cave is the only site in Serbia with a complete stratigraphic sequence from the late Mousterian to the Gravettian, containing abundant macrofaunal assemblages and diagnostic artefact industries. Here we present AMS-dates using ultrafiltration and preliminary zooarchaeological results from the Mousterian- and Aurignacian-age faunal remains, which suggest the successive pres- 
ence of late Neanderthal and early AMH populations in Serbia and offer the first evidence about their respective diets, subsistence strategies, and ecological adaptations in the region.

\section{THE SITE, INDUSTRIES, AND RADIOMETRIC CHRONOLOGY Šalitrena Pećina}

Šalitrena Pećina is located near the village of Breždje, in the canyon of the Ribnica River, around $100 \mathrm{~km}$ southwest of Belgrade (Figure 1). The cave is on the left bank at 277 masl. Preliminary excavations began in the 1980s (Jez and Kaluderovic 1985), although it was not until 2004 when, under the direction of B. Mihailović, excavations were carried out using modern techniques and intensive recovery methods (B. Mihailović 2008, 2013; Mihailović et al. 2014). Excavations are still ongoing. The cave entrance is $20 \mathrm{~m}$ wide, facing west, overlooking (and $20 \mathrm{~m}$ above) the present-day river course. It is divided by a large rock into two passages of nearly $40 \mathrm{~m}$ in length. The interior of the cave is around $600 \mathrm{~m} 2$, with a total length of $135 \mathrm{~m}$. Rich archaeological assemblages have been retrieved from an excavated area totalling $40 \mathrm{~m} 2$, subdivided into three main zones (Figure 2): the cave mouth (divided into six trenches: B, C, D, E, $\mathrm{G}$ and $\mathrm{EG}$ ), the interior (12 $\mathrm{m}$ from the entrance, with two trenches: $\mathrm{H}$ and HSP), and near the southwest corner (Trench F).

\section{Industries}

Evidence of Paleolithic human activity is found in the cave mouth in level 3, which together with level 4 is attributed to the Gravettian (Mihailović and Mihailović 2007)
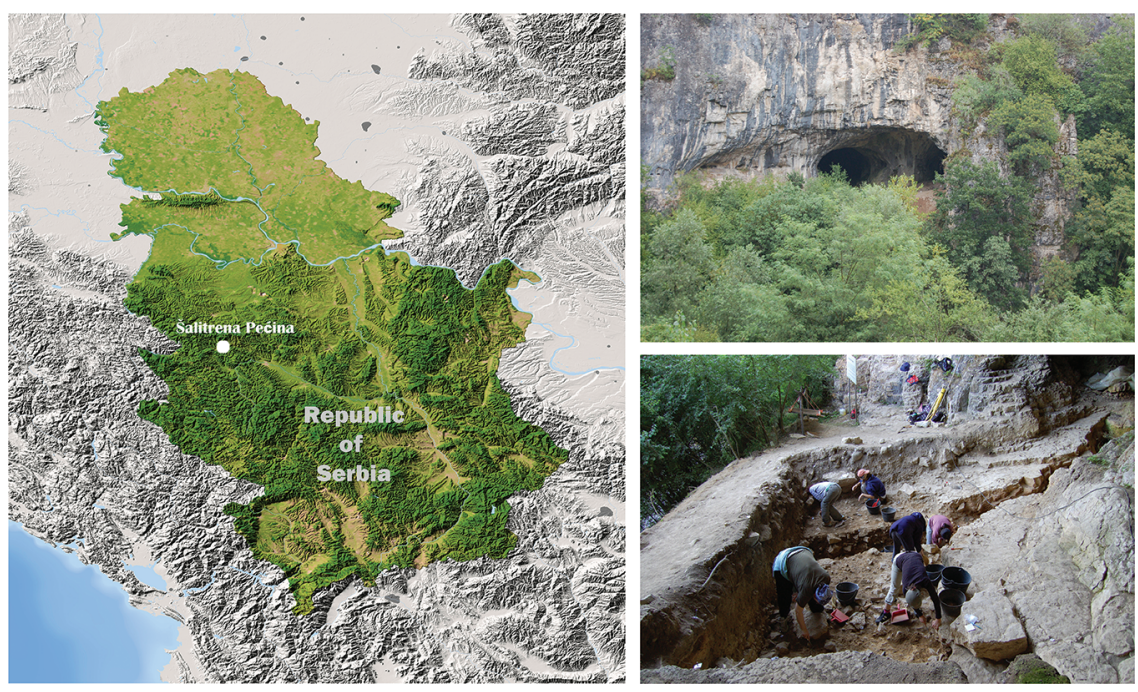

Figure 1. Location of Šalitrena Pećina (Mionica, Serbia). Exterior view of the cave and view of the excavation area in the cave mouth. 


\section{Šalitrena Pećina}

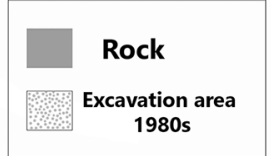

5 m
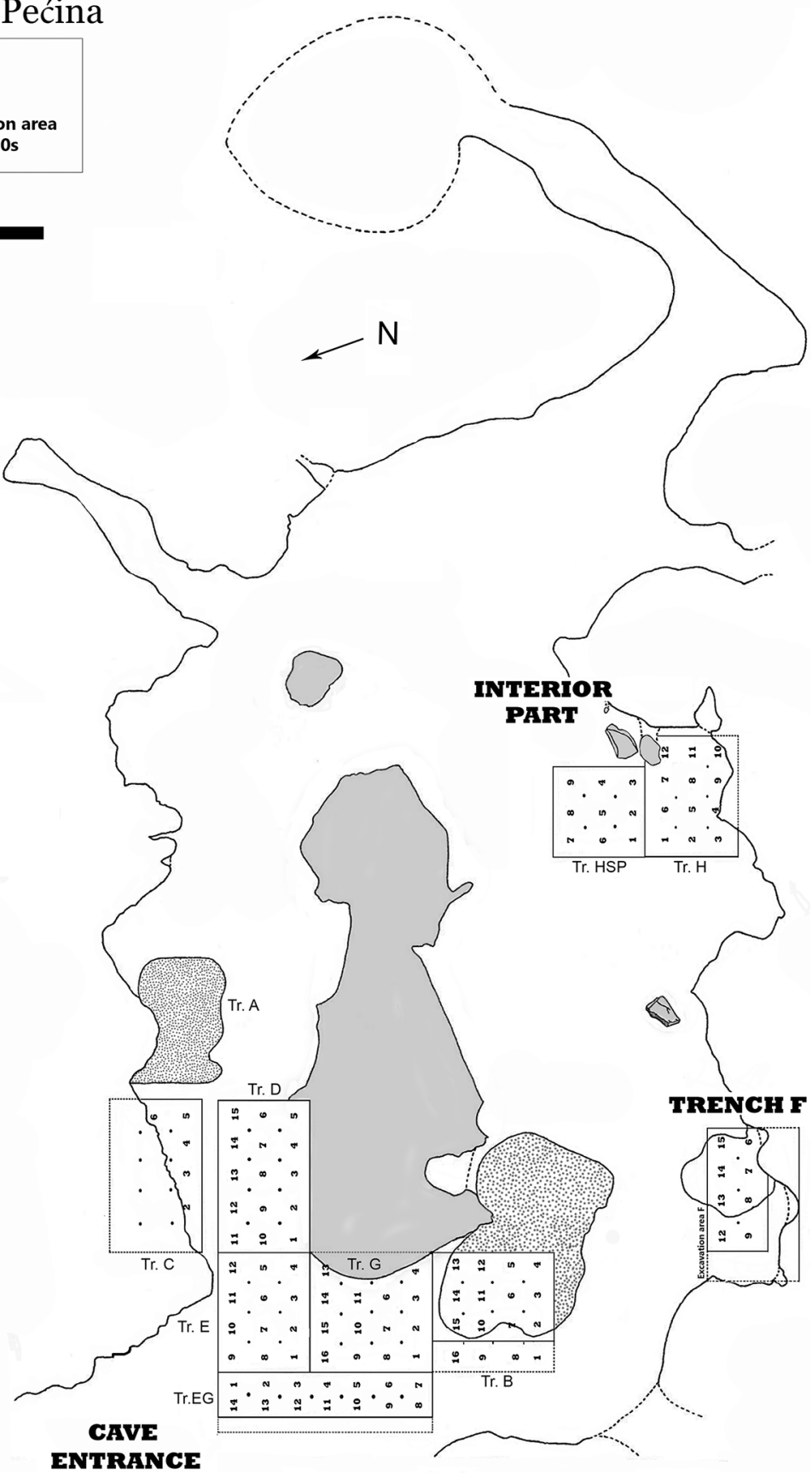

Figure 2. Plan of Šalitrena Pećina showing excavation areas. (redrafted by L. Agudo from original by J. Marković) 
(Figure 3). Level 5a contains Aurignacian artifacts and levels 5b, 5c, and 6 contain Middle Paleolithic ones. Lithic assemblages from levels 5b, 5c, and 6 can be ascribed to the typical Balkan Mousterian with side scrapers, Mousterian points and Levallois artifacts. This type of industry is present at many sites in northern Bosnia and western Serbia (D. Mihailović 2008). During the 2014 season of excavation, Middle Paleolithic assemblages with leaf-like points were found. The identification of such leafpoint techno-complexes indicates that they were distributed not only in central Europe and the eastern Balkans, but also in the peri-Pannonian area (Mihailović et al. 2014). The Aurignacian industry from level $5 \mathrm{a}$ is distinctive and differs from other Aurignacian sites in northern Bosnia, and in Romanian and Serbian Banat (Mihailović et al. 2011), given a high percentage of carinated endscrapers, burins, and retouched and unretouched bladelets. The composition, technological, and typological characteristics of the artifacts indicate this industry can be more closely associated with the early Aurignacian in central and western Europe. Aurignacian level 5a also contains mineral pigments, a dentalium (Antalis sp.) shell bead (Mihailović and Mihailović 2009), and several bone tools, particularly bone points. In the Mousterian levels several retouched bones (fragments of large and medium-sized mammal diaphyses) were found. The study of bone technology is currently ongoing.

Unlike in the cave mouth, Aurignacian level 2 in the interior area of the cave does not contain bladelets and instead has larger tools, including typical Aurignacian longblades and endscrapers on blades. Whether these differences are the result of different activities or represent different periods of use is still being explored. Level 3 industries in the interior of the cave are similar to those of the Mousterian in the cave mouth area. Between the exterior and interior areas, Trench F (near the southwest corner) has yielded a distinctive Aurignacian assemblage in one level (Level 5). The presence of cave bear remains and carnivore evidence (hyena gnaw marks) in the interior part of the cave is noteworthy. Cave bear is commonly found in karstic deposits in Serbia, as speleological, paleontological, and archaeological explorations have shown in the past few decades (Cvetković and Dimitrijević 2014).

\section{Radiocarbon Dates}

Nine radiocarbon measurements have been obtained from the Mousterian and Aurignacian levels of Šalitrena Pećina, sampled from both the cave mouth and interior areas. Of these radiocarbon dates, eight were from faunal bone/tooth collagen and one from a shell (Antalis sp). Ultrafiltration techniques were used for the bone measurements and CarDS methodologies were applied to the shell specimen as described in Bronk Ramsey et al. (2004) and Douka et al. (2010), respectively. Of the radiocarbon samples, two measurements are beyond the range of the radiocarbon method (Table 1). Mousterian-level dates at Šalitrena Pećina indicate a presumed Neanderthal occupation ranging between 42.8 and $39.3 \mathrm{cal}$ BP, whereas probable modern human occupation at the cave is dated to between 36.7 and $33.8 \mathrm{cal}$ BP. According to these 


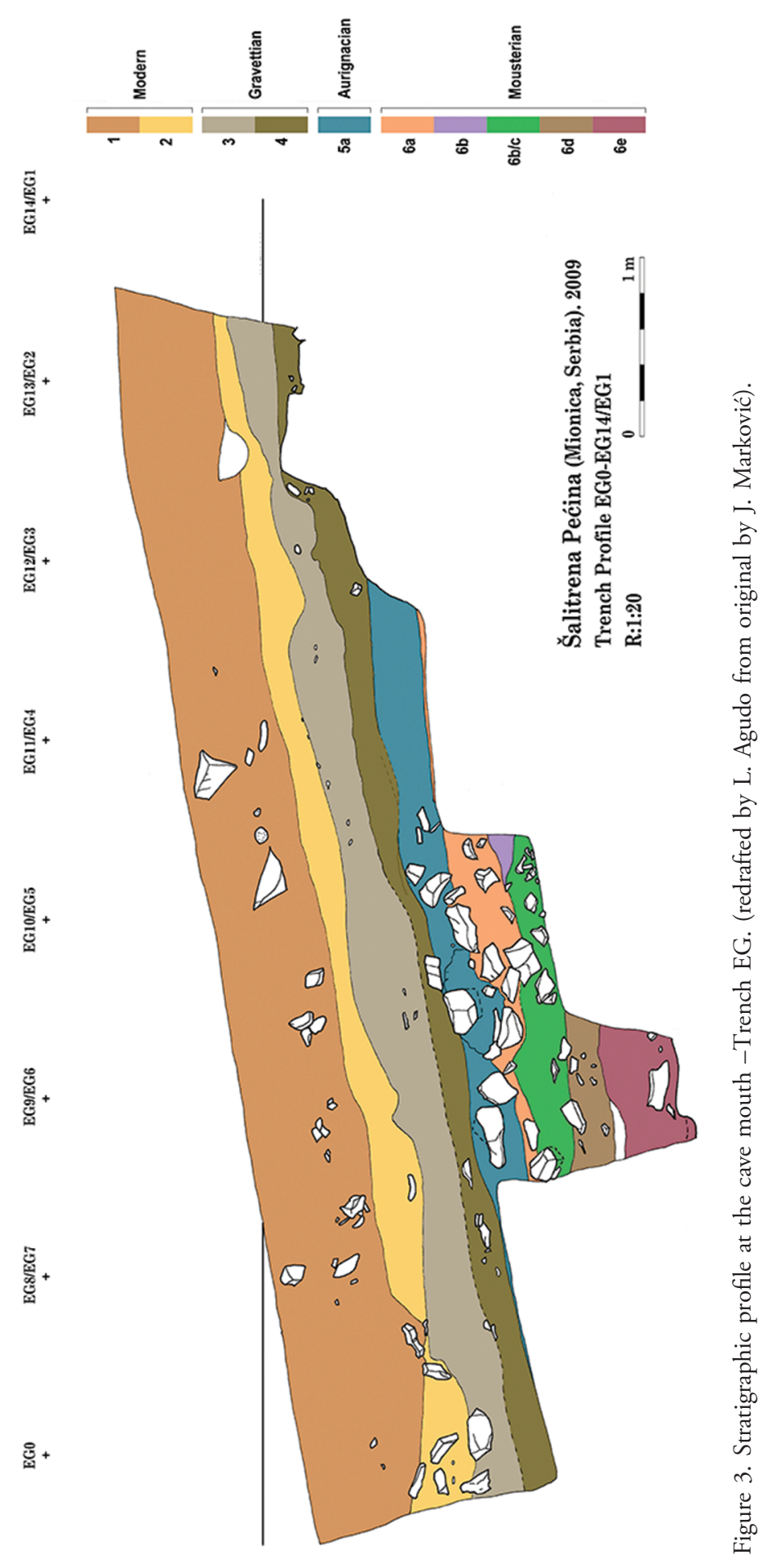




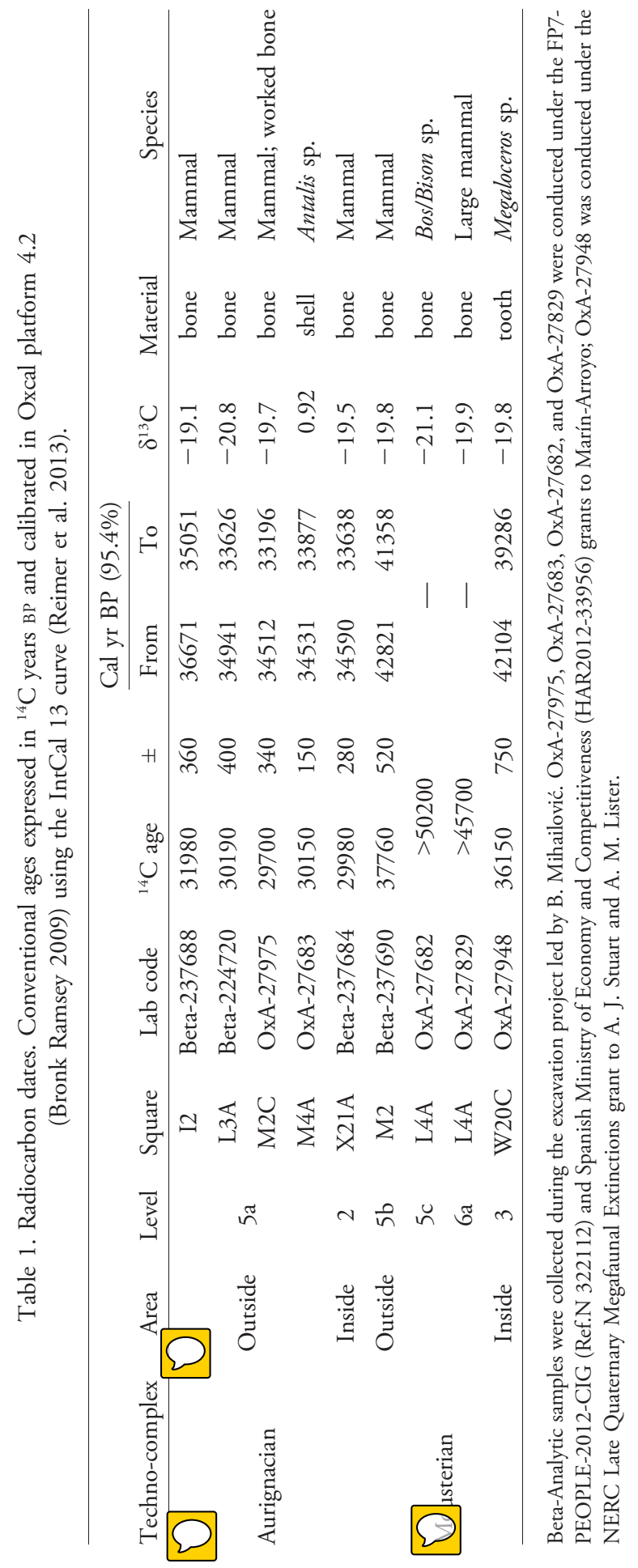


radiocarbon dates, there would have been a depositional hiatus of several thousand years between cave mouth levels 5b (Mousterian) and 5a (Aurignacian).

The modeled age for the end of the European Mousterian has been estimated as lying between 41 and $39 \mathrm{ka}$ cal вр based on material from the sites of Spy (Belgium) and Bombrini (northwestern Italy) (see Higham et al. 2014: Supplementary Information). Current dating evidence supporting a late Neanderthal survival only in southern latitudes (e.g., Vindija, Zafarraya, Gorham's Cave) is now regarded as problematic (Higham et al. 2006b; Wood et at. 2013). Therefore, the Mousterian occupations at Šalitrena Pećina might support the hypothesis of a withdrawal of Neanderthal groups from the fluvial Danube plains into the mountainous territories to the south (Mihailović et al. 2011).

In addition, an earlier presence of $\mathrm{AMH}$ in Europe has been confirmed for the Uluzzian in the Italian Peninsula (between 45 and $40 \mathrm{ka}$ cal BP; Douka et al. 2014), the Aurignacian of northern Iberia (c. 42 ka cal Bp; Zilhão 2006; Wood et al. 2014), the southwest German site of Geißenklösterle (between 43 and 41 ka cal BP; Higham et al. 2012), and the directly dated KC4 maxilla of Kent's Cavern in the UK (between 44.2 and $41.5 \mathrm{ka} \mathrm{cal} \mathrm{BP;} \mathrm{Higham} \mathrm{et} \mathrm{al.} \mathrm{2011).} \mathrm{All} \mathrm{of} \mathrm{these} \mathrm{evidence} \mathrm{suggests} \mathrm{that} \mathrm{the}$ spread of AMH throughout Europe was rapid and that the period of coexistence with Neanderthals was shorter than previously thought, potentially even within the error ranges of chronological models (Wood et al. 2014). The Danube Valley could have been a major colonization route into central and western Europe from the Near East, as evidenced by the sites of Temnata and Bacho Kiro (Layer 11) in Bulgaria with radiocarbon dates slightly older than those of the Uluzzian levels at the Grotta del Cavallo (Douka et al. 2014; Mellars 2011). In Serbia, Tabula Traiana Cave, located in the Danube Gorge, provided the first radiocarbon dates of the early Aurignacian ranging between 41.5 to $34.5 \mathrm{ka}$ cal вр (Borić et al. 2012), with a small lithic and faunal assemblage attributed to short human occupations, whereas the dates at Šalitrena Pećina indicate a later and more intense occupation by modern humans. Nevertheless, the hiatus between levels 5b and 5a in Šalitrena Pećina might suggest no interaction between Neanderthals and AMH here during a period of ca. 6,000 years (assuming that in Serbia the Aurignacian only represents $\mathrm{AMH}$, notwithstanding the lack of associated human fossils).

Here, archaeozoological evidence of macromammals recovered at Šalitrena Pećina offers an exceptional, albeit preliminary, opportunity to unravel the diet and subsistence strategies carried out by both human species and to reconstruct the paleoecological niches exploited in this eastern European region.

\section{Zooarchaeological Analyses}

The zooarchaeological analyses were conducted at the National Museum of Belgrade, where the material is currently curated. Only macromammalian remains from the cave mouth and Trench F that are securely attributed to the Aurignacian (level 5a in the cave mouth and level 5 in Trench F) and to the Mousterian (levels 5b, 5c, and 6 
in the cave mouth) are analyzed here. The comparative collection at the Department of Archaeology at the University of Belgrade and the fossil collection from the Natural History Museum in London were used to determine taxa and skeletal elements. Each bone recovered during the excavation was spatially attributed to the square, sub-square, and archaeological level where it was found, complete with an individual identification number. Dry sieving during the excavation allowed the recovery of small anatomical elements as well.

Owing to small sample sizes, the Mousterian and Aurignacian assemblages were each grouped to permit preliminary comparison. The identified bones were quantified by applying the following indices: Number of Identified Specimens (NISP), Minimum Number of Individuals (MNI), Minimum Number of Skeletal Elements (MNE) following Marín-Arroyo (2009b), and Minimum Animal Units (MAU; Binford 1978). Biomass calculations were made by multiplying values of useable meat (following the methodology applied in Marín-Arroyo and González Morales 2009) using MNI. Because of the high degree of fragmentation, the specimens that could not be identified taxonomically by any distinctive landmark were grouped by size into megafauna (rhinoceros/megaloceros), large (bovine/horse), medium (red deer/ibex), and small (chamois/roe deer) ungulates. Unidentifiable carnivore remains were also grouped into large (cave bear, cave lion, leopard), medium (wolf, hyena, lynx), and small (fox, wild cat, mustelids).

Every skeletal element $>2 \mathrm{~cm}$ long was examined under a LEICA S8 APO stereoscope with $10 \times$ eyepieces to identify any biostratinomic and diagenetic alterations, such as cut marks (grouped into skinning, dismembering, and defleshing categories following Binford 1981 and Pérez Ripoll 1992), hammerstone percussion marks [including conchoidal notches (Bunn 1981; Capaldo and Blumenschine 1994; Pickering and Egeland 2006), type and angle of fracturing (fresh green vs. old dry following Villa and Mahieu 1991), and thermoalterations. Carnivore and rodent gnaw marks and traces of digestion were also identified, as well as other biological and chemical alterations, such as weathering (Behrensmeyer 1978), root etching, insect/fungus activity, carbonate deposits, polishing (Fisher 1995; Lyman 1994; Shipman 1981), and dissolution or mineral coatings (mainly mineral manganese; see Marín-Arroyo et al. 2008, 2014).

Ungulate mortality patterns (i.e., juvenile, prime, or older individuals) were determined by using both dental eruption and wear stages of pd4, P4, and M3, following Stiner $(1991,2005)$. Dietary breadth and the degree of anthropogenic use of the environment have been evaluated using the inverse of Simpson's index. This index can vary between 1 and the number of hunted species, the former when the abundance of one species is overwhelming and the latter when all species are equally consumed.

Differential transport of carcasses and the related functionality of the site were investigated using bivariate correlations of \%MAU with utility (in terms of \%MGUI, following Binford 1978) and bone survivorship (represented by bone mineral density, following Lam et al. 1999). Correspondence analysis was used to compare the skeletal profiles found in the assemblages with theoretical profiles deriving from different kinds 
of carcass butchery practices at kill sites and various degrees of attrition (Marín-Arroyo 2013). This method enables comparative evaluation between species and periods. When resources were scarce in the vicinity of a site and changing residency is not likely to improve the situation, mobility and catchment areas would have to increase. As travelling times become longer, differential transport of carcasses will intensify to maximize the energy contributed to the base camp (Cannon 2003; Marín-Arroyo 2009a). The possible ways in which human groups might have processed carcasses at kill sites are summarized in Table 2. Once elements were discarded and deposited at the base camp, they undergo attritional processes of varying intensity, characterized by a parameter $(\beta)$ that can vary between 0 and 8 . Thus, the likelihood of survival of a single element, in the absence of better estimates, is obtained as an exponential function of the bone density (Rogers 2000). A value of $\beta=1$ would indicate that only half the bones survive, whereas if $\beta=2$, the survival percentage is reduced to $25 \%$, and so on.

Finally, the relationship between the consumed fauna and ecological niches was investigated by estimating the catchment areas associated with the site, characterizing the local relief, following the methodology described by Marín-Arroyo (2009a). A digital model of the terrain around the sites was produced, including the continental shelf (ASTER GLOBAL DEM and ETOPO1 data). Travelling times across the territory were estimated with empirical formulas depending on distance, slope angles, movement direction (uphill or downhill), and the existence of nearly insurmountable barriers (Marín-Arroyo 2010). To define the preferred biotopes for plains and montane species, within the boundaries determined by the catchment area, a threshold value of $10 \%$ slope has been fixed to differentiate areas related to one or the other group of taxa. Beyond that value, grazing suitability is depleted (Holechek et al. 1998)

Table 2. Proposed strategies of carcass processing at a kill site and transport to a basecamp. $\mathrm{P}$ can take a value of $0,0.2,0.4,0.6,0.8$, or 1 . The head is represented by mandibles; the axial skeleton, by vertebrae, ribs, pelvis, and sacrum; the forelimb, by scapula, humerus, radius/ulna, metacarpals, carpals, and phalanges; and the hindlimb, by femur, tibiae, metatarsals, astragalus, calcaneum, tarsals, and phalanges.

\begin{tabular}{lccccc}
\hline & & \multicolumn{4}{c}{ Transport to the site } \\
\cline { 3 - 6 } Strategy & Probability & Head & Axial & Forelimb & Hind limb \\
\hline Complete contribution & 1 & Yes & Yes & Yes & Yes \\
Axial processing at the kill site & $(1-\mathrm{P}) / 2$ & No & Yes & Yes & Yes \\
& $(1-\mathrm{P}) / 2$ & No & No & Yes & Yes \\
& $\mathrm{P}$ & Yes & Yes & Yes & Yes \\
Appendicular processing at kill site & $(1-\mathrm{P}) / 2$ & No & Yes & No & Yes \\
& $(1-\mathrm{P}) / 2$ & No & Yes & No & No \\
\hline
\end{tabular}




\section{RESULTS \\ Quantification of the Faunal Assemblage}

The Mousterian and Aurignacian levels collectively yielded 2,604 faunal remains (bones and teeth), $14 \%$ of which were identifiable to taxa and $34 \%$ to anatomical part. Owing to the state of fragmentation of the assemblage, a minimum number of only 463 anatomical elements (MNE) were quantified (18\% of NISP). The total MNI represents 75 different ungulate, carnivore, rodent, leporid, and bird taxa. The distribution of NISP, MNE, and MNI values per level and species is presented in Table 3. The assemblage composition of ungulate and carnivores is similar in the Mousterian and Aurignacian levels. Ungulates represent 64\% in the Mousterian and 54\% in the Aurignacian, while $35 \%$ of the assemblage in each cultural period is attributable to carnivores. Other taxa, such as leporid, rodent, bird, and fish remains, represent $2 \%$ in the Mousterian and $11 \%$ in the Aurignacian levels, respectively.

\section{Origin of the Deposit}

Determining the taphonomy of the deposit is essential for identifying the agents involved in the formation of the assemblage, and it is crucial to ascertain before any interpretation about subsistence can be made (Lyman 1994). First, to determine if the deposit was accumulated primarily by humans or carnivores, the percentage of long bones with cut marks and gnawing marks was calculated. As shown in Figure 4, experimental and ethnographic results from control samples have been combined with the aim of distinguishing the agent of accumulation of large and medium-sized mammal bones in Šalitrena Pećina. To do so, typical cut-mark percentage data have been obtained from previous studies by Dominguez-Rodrigo (1997: Table 2), Selvaggio (1998: Table 6), Capaldo (1998: Table 12), Lupo and O'Connell (2002: Table 6), Dominguez-Rodrigo and Barba (2005: Table 3); the tooth-mark data were taken from Blumenschine (1995: Table 3), Capaldo (1998: Table 12), Selvaggio (1998: Table 6), and Marean et al. (2000: Table 3).

The results show that long bones from large and medium-sized mammals from both Aurignacian and Mousterian levels were clearly brought to the cave by humans, as they have significantly more butchery marks than those originating from carnivore activity. In particular, medium-sized mammal bones from Mousterian level 6 fall within the typical range of being accumulated first by humans and later scavenged by carnivores, whereas those from level $5 \mathrm{c}$ are not clearly attributed to humans because there is an overlap between "carnivore to human" and "human to carnivore" patterns (Figure 4). As well as those occurring on long bones, cut marks were found on other skeletal elements, such as crania, axial elements, metapodials, and phalanges. Thus, for large mammals, the percentage of butchering marks is $13.6 \%$ in the Mousterian assemblages and 6.9\% in the Aurignacian ones, and for medium-sized mammals, such anthropogenic marks were found on $5 \%$ and $2.7 \%$ of the Mousterian and Aurignacian assemblages, respectively. Carnivore marks on large mammals are 
almost identical during the Mousterian (3.7\%) and Aurignacian (3.8\%), and for medium-sized mammals the percentage is lower during the Mousterian $(0.7 \%)$ than in the Aurignacian (2.7\%). Among small mammal bones, neither cut marks nor gnaw marks were found, and no evidence of small, fast game exploitation has been identified in either period. In summary, the deposit is clearly linked to human activity and can be interpreted as evidence of human subsistence.

In addition to butchering marks identified on large and medium-sized mammals, other anthropogenic modifications have been recognized in the assemblage (Table 4). In particular, $30 \%$ of the ungulate bones in the Mousterian levels and $17 \%$ in $\mathrm{Au}-$ rignacian levels show evidence of fresh bone fractures. Flake scars on the medullary surface were identified on $9 \%$ of the bones in Mousterian and $8 \%$ in Aurignacian levels. Signs of thermoalteration on ungulate remains were found on $4 \%$ of the bones in Mousterian and 4\% in Aurignacian levels. Figure 5 shows some of the biostratinomic modifications identified on animal bone surfaces.

There are abundant signs of marrow extraction in all levels. The degree of fragmentation (measured as the quotient between NISP and MNE) correlates positively and significantly with the Marrow Index (1) for medium-sized mammals in the Mousterian (levels 5b and 5c) and (2) for large mammals in all of the Mousterian and Aurignacian levels, except in Trench $\mathrm{F}$ (Table 5).

Within the Aurignacian level in Trench F, anthropogenic activity, although apparent, is more infrequently observed within the assemblage, whereas gnawing marks were identified in a larger percentage than in other strata. The location of this trench, toward the interior and close to the south wall, made it a suitable place for carnivore denning and, at the same time, made it less appealing for human activities, serving for human groups more as an area of transit to the rear part of the cave. Three different cave bear individuals (one infantile, one prime-age and one old) were identified in the trench in addition to hyena and fox remains. This sheltered zone could have been used both by cave bears and as a location where secondary carnivore scavenging activities took place. Therefore, Trench $\mathrm{F}$ has been excluded from further human subsistence analysis and interpretation.

Other biostratinomic and diagenetic alterations are summarized in Table 6. Within the cave mouth, Mousterian levels 5b, 5c, and 6 are less sheltered than areas deeper the cave, so these levels might have suffered several episodes of ponding and water flow, with intensive washing being indicated by the larger number of bones showing evidence of dissolution. Thus, the substantial number of bones with weathering suggests that there were significant changes in temperature/humidity at the times that levels $5 \mathrm{~b}$ and 6 were being deposited. The trampling activity in level 6 could be a result of human activity, as well as the great abundance of detritus that fell from the roof of the cave during the Mousterian period, which is indicative of a cold period. Finally, in Trench F, the high proportion of polished bones (up to 19\%) is likely due to cave bear trampling, as this area served as a corridor to the interior of the cave. 


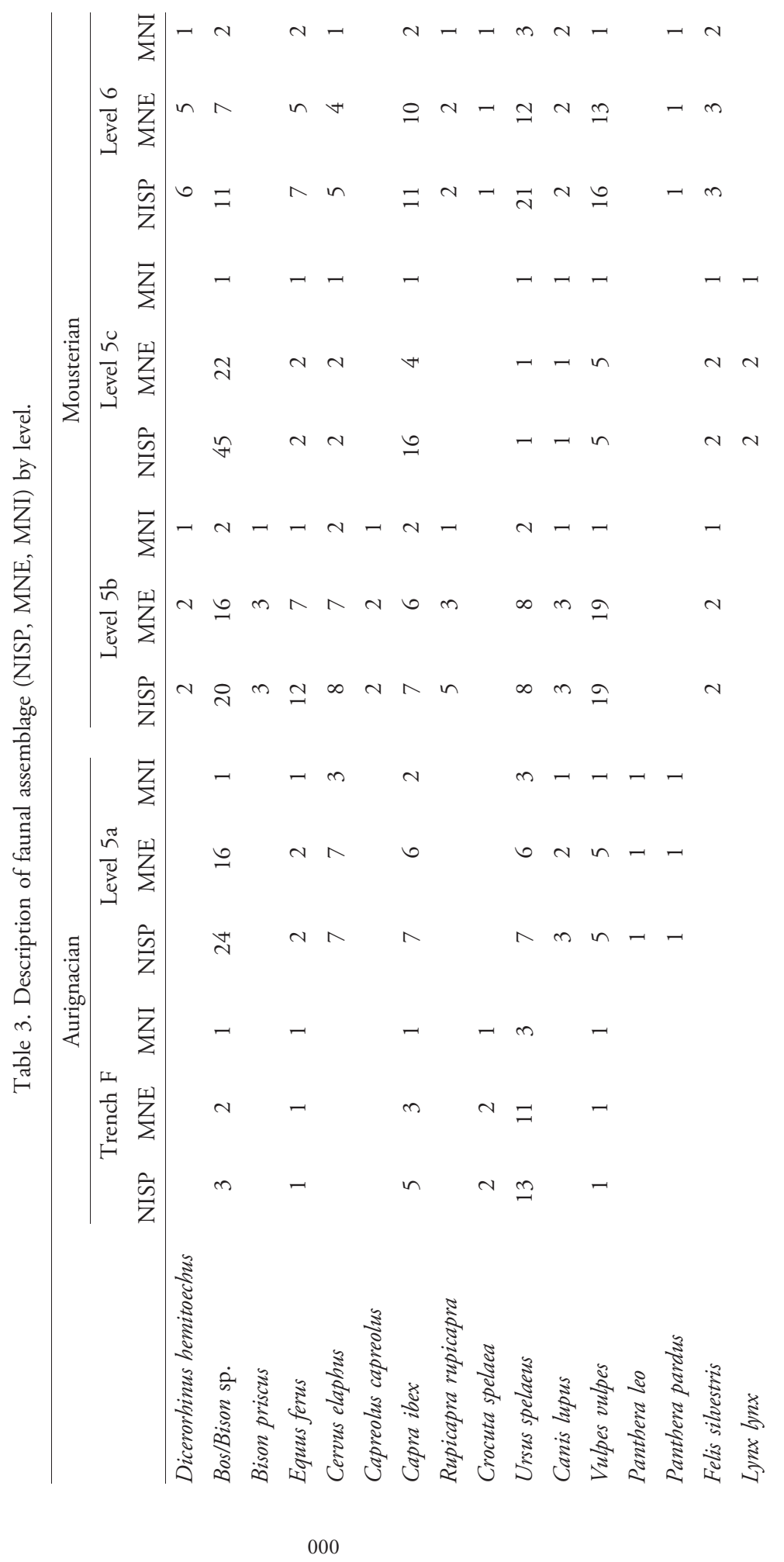




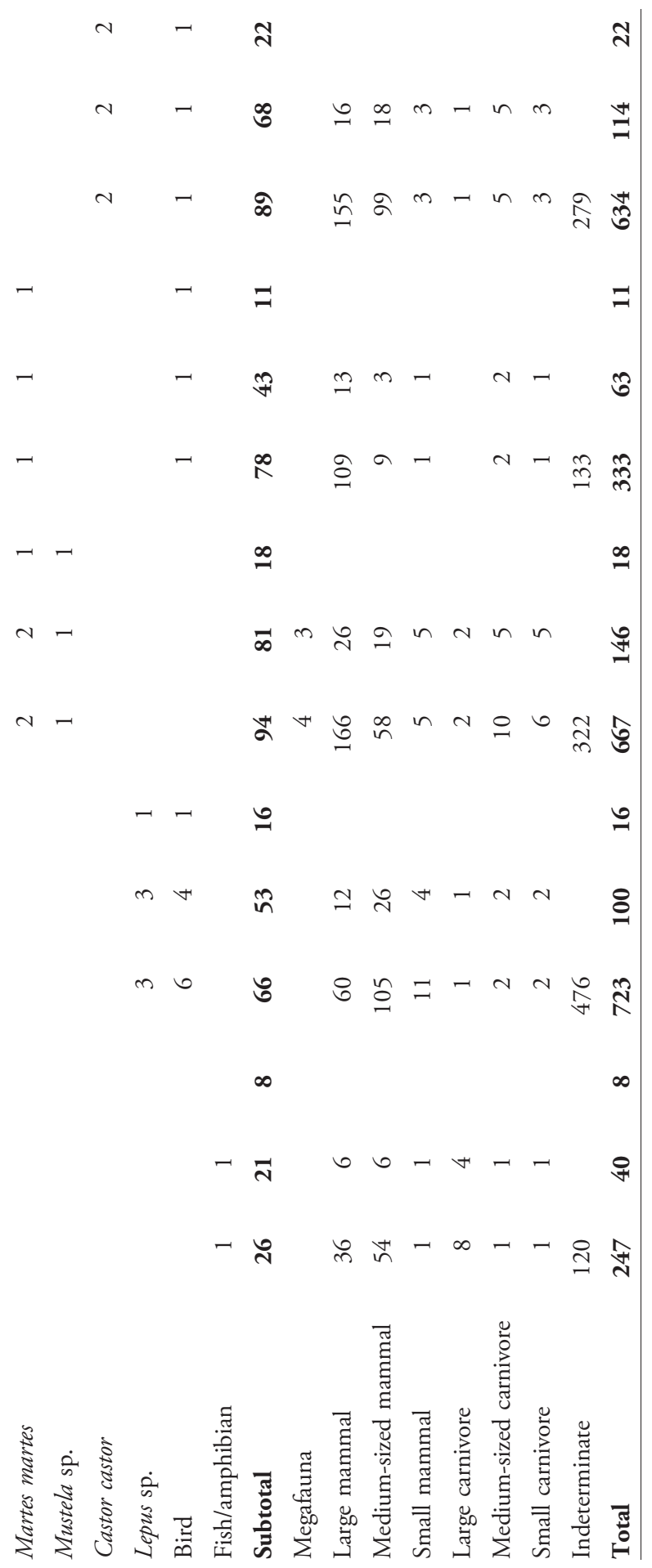




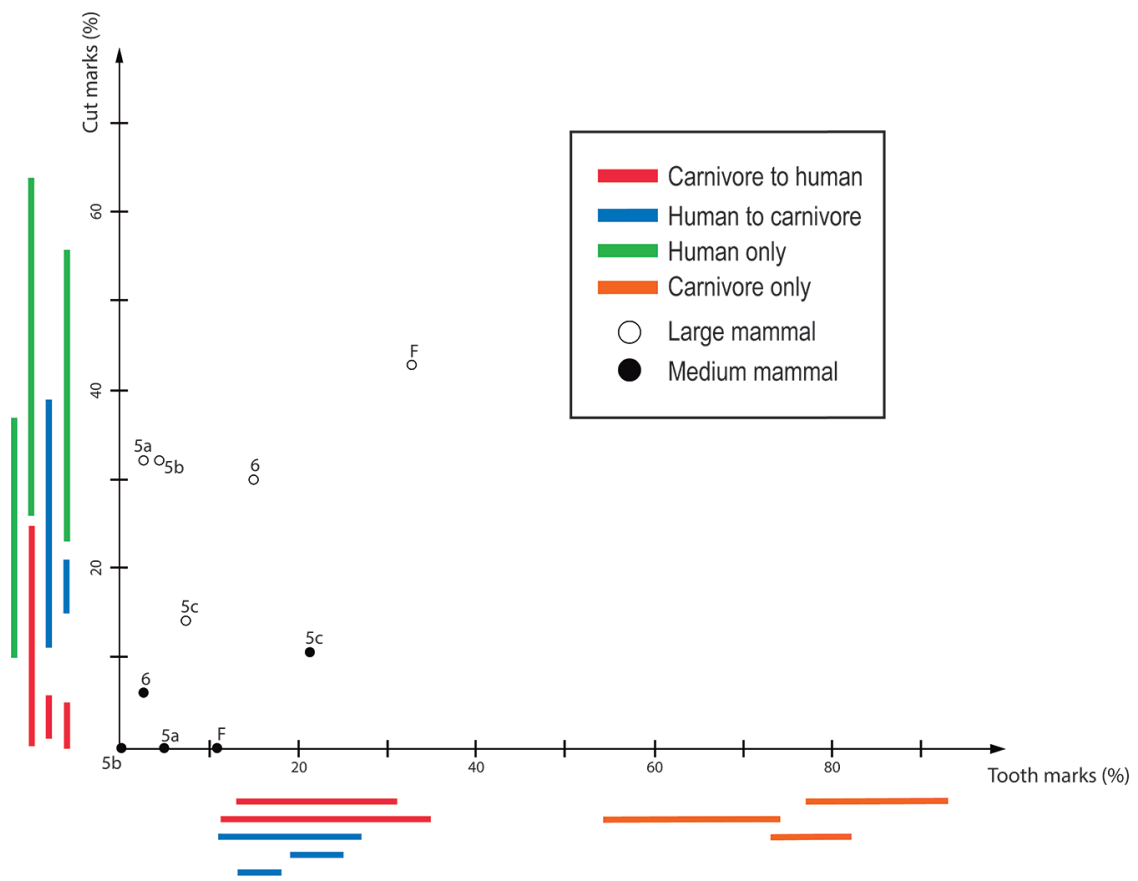

Figure 4. Percentages of large and medium-size mammal long bones with cut and tooth marks in the Mousterian (5b, 5c, 6) and Aurignacian (5a and F) levels at Šalitrena Pećina, compared with findings from ethnographic and actualistic studies. Sources are listed in the text.

\section{Subsistence Strategies and Ecological Niche Exploitation}

Table 7 shows the taxonomical representation of ungulates at Salitrena Pećina in terms of NISP and biomass. On the one hand, in terms of NISP, bovines (followed by ibex, horse, and deer) are the most abundant taxa in the Mousterian assemblage, which is consistent with the topographic location of the cave very close to open plains. Those flat areas were the favored habitat for the bovines (Figure 6a), whereas the habitat of ibex is around a 2-hour walk from the site. Other identifiable ungulates, which appear in relatively small numbers, are rhinoceros and small mammals, such as roe deer and chamois. In the Aurignacian deposit, bovines are the most important taxa, with higher percentages than in the Mousterian assemblage, followed by red deer and ibex, with horse being scarcely represented. However, the differences in terms of NISP between the Mousterian and Aurignacian are nearly imperceptible when comparing the size of the prey. Medium-sized mammals are slightly more abundant during the Aurignacian, and small mammals were only identified in Mousterian assemblages.

On the other hand, when considering the biomass contributed by the different species in each cultural assemblage, there are some differences vis-à-vis those shown by NISP figures (Table 7). First, when rhinoceros is present (only during the Mous- 
Table 4. Summary of occurrence (NISP) of key taphonomic traits by mammal size classes

\begin{tabular}{|c|c|c|c|c|c|c|c|c|}
\hline & & $\begin{array}{l}\text { NISP w/o } \\
\text { teeth }\end{array}$ & $\begin{array}{l}\text { Cut } \\
\text { marks }\end{array}$ & $\begin{array}{l}\text { Spiral } \\
\text { fracture }\end{array}$ & $\begin{array}{l}\text { Impact } \\
\text { scars }\end{array}$ & Burning & $\begin{array}{l}\text { Tooth } \\
\text { marks }\end{array}$ & Digestion \\
\hline \multirow{10}{*}{ 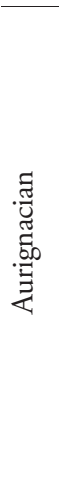 } & Trench F & & & & & & & \\
\hline & Large & 39 & 7 & 8 & 2 & 0 & 10 & 0 \\
\hline & Medium & 53 & 1 & 3 & 0 & 0 & 4 & 0 \\
\hline & Small & 1 & 0 & 0 & 0 & 0 & 1 & 0 \\
\hline & Total & 93 & 8 & 11 & 2 & 0 & 15 & 0 \\
\hline & Level 5a & & & & & & & \\
\hline & Large & 76 & 13 & 31 & 12 & 5 & 1 & 0 \\
\hline & Medium & 111 & 7 & 8 & 9 & 8 & 4 & 2 \\
\hline & Small & 11 & 0 & 0 & 0 & 0 & 0 & 1 \\
\hline & Total & 198 & 20 & 39 & 21 & 13 & 5 & 3 \\
\hline \multirow{15}{*}{ 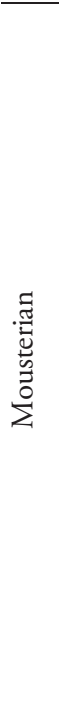 } & Level 5b & & & & & & & \\
\hline & Large & 187 & 39 & 56 & 26 & 7 & 10 & 1 \\
\hline & Medium & 63 & 7 & 10 & 3 & 7 & 0 & 0 \\
\hline & Small & 11 & 0 & 4 & 2 & 1 & 0 & 0 \\
\hline & Total & 261 & 46 & 70 & 31 & 15 & 10 & 1 \\
\hline & Level 5c & & & & & & & \\
\hline & Large & 134 & 24 & 71 & 18 & 0 & 17 & 0 \\
\hline & Medium & 17 & 6 & 7 & 1 & 3 & 5 & 0 \\
\hline & Small & 1 & 0 & 0 & 0 & 0 & 0 & 0 \\
\hline & Total & 152 & 30 & 78 & 19 & 3 & 22 & 0 \\
\hline & Level 6 & & & & & & & \\
\hline & Large & 170 & 32 & 46 & 6 & 2 & 10 & 1 \\
\hline & Medium & 111 & 22 & 17 & 7 & 5 & 14 & 0 \\
\hline & Small & 5 & 0 & 0 & 0 & 0 & 0 & 0 \\
\hline & Total & 286 & 54 & 63 & 13 & 7 & 24 & 1 \\
\hline
\end{tabular}

terian), it could represent, in theory, the most important part of the diet. However, the number of skeletal elements of rhinoceros is relatively small and, in this case, we consider that the MNI is inflating the real representation of this taxon. Therefore, excluding rhinoceros, $63 \%$ of the Neanderthals' diet was based on bovines, the taxon that provided the greatest amounts of meat, grease, and fat to the diet. It was followed by horse $(15 \%)$ and red deer $(16 \%)$ and, to lesser extents, by ibex $(6 \%)$ and chamois and roe deer $(0.4 \%)$. The AMH diet was composed of $41 \%$ bovines, followed by $36 \%$ red deer, $15 \%$ horse, and $7 \%$ ibex (Table 7). Thus, both Neanderthals and modern humans in Šalitrena Pećina relied on the exploitation of bovines, although the percentage of medium-sized mammals (red deer) is higher in the Aurignacian (36\%) 


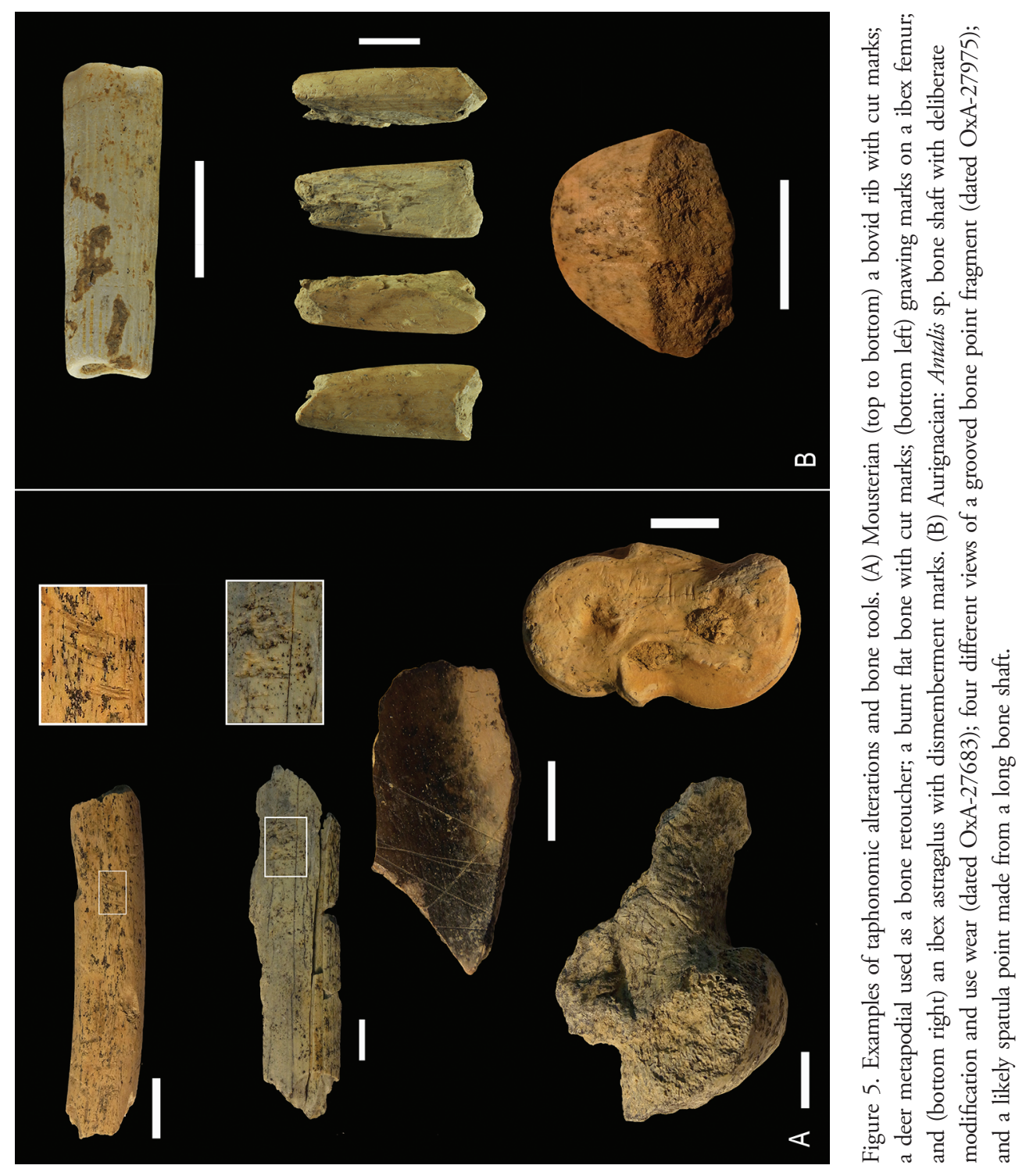


Table 5. Spearman's correlation ( $\rho s)$ between NISP/MNE and Marrow Index for mammals by size class (significant if $p<0.05$ ). Positive and significant correlations are shaded.

\begin{tabular}{clcc}
\hline & Large & Medium & Small \\
\hline Aurignacian & & & \\
Trench F-Level 5 & 0.126 & 0.058 & 0.27 \\
Level 5a & 0.548 & 0.784 & 0.192 \\
& 0.628 & 0.205 & 0.202 \\
Mousterian & 0.001 & 0.325 & 0.344 \\
Level 5b & & & \\
& 0.54 & 0.405 & 0.036 \\
Level 5c & 0.005 & 0.045 & 0.864 \\
& 0.46 & 0.609 & -0.195 \\
Level 6 & 0.021 & 0.001 & 0.35 \\
& 0.502 & 0.333 & 0.206 \\
\hline
\end{tabular}

than the Mousterian (16\%). There are no significant differences between the Mousterian and Aurignacian assemblages in the exploitation of horse and ibex, as those taxa show similar percentages.

The inverse Simpson index (Figure 7) indicates higher values in Mousterian levels $5 \mathrm{~b}$ and 6 , which could be interpreted as a wider diet at that time. However, Mousterian level 5c and Aurignacian level (5) ow lower values, indicating a narrower diet (Figure 7). Hence, we cannot reject the possibility that the change observed in taxonomical composition between the different levels could have been caused by other factors, such as the season of occupation, site function, group size, or archaeological

Table 6. Diagenetic modifications reported by \%NISP

(in relation to the total NISP of the assemblage)

\begin{tabular}{lccccc}
\hline & Aurignacian & & \multicolumn{3}{c}{ Mousterian } \\
\cline { 2 - 5 } \cline { 5 - 6 } Source/Type of Modification & Level 5a & & Level 5b & Level 5c & Level 6 \\
\hline Rodent & 14.8 & & 0.7 & 0 & 0 \\
Insect/fungus & 17.3 & & 1.9 & 0 & 0 \\
Root etching & 0.6 & & 0.7 & 0 & 0 \\
Carbonate & 7.9 & & 1.8 & 0.3 & 3.2 \\
Coating & 12.9 & & 37.5 & 6.6 & 44.8 \\
Dissolution & 5.8 & 12.1 & 0.6 & 3.8 \\
Trampling & 1.4 & & 1.9 & 0.3 & 17.8 \\
Polishing & 18.6 & & 3.1 & 0 & 4.9 \\
Weathering & 1.2 & 15.1 & 1.2 & 19.7 \\
\hline
\end{tabular}


Table 7. Taxonomical representation (by species and size class) of ungulates in terms of \%NISP and \%biomass (in relation to the total ungulate assemblage)

\begin{tabular}{|c|c|c|c|c|c|}
\hline & \multicolumn{2}{|c|}{$\%$ NISP } & \multicolumn{3}{|c|}{$\%$ Biomass } \\
\hline & Aurignacian & Mousterian & Aurignacian & Mousterian & $\begin{array}{c}\text { Mousterian } \\
\text { (w/o rhinoceros) }\end{array}$ \\
\hline \multicolumn{6}{|l|}{ By Species } \\
\hline $\begin{array}{l}\text { Dicerorhinus } \\
\text { hemitoechus }\end{array}$ & 0 & 5 & 0 & 43 & 0 \\
\hline Bos/Bison sp. & 59 & 48 & 41 & 36 & 63 \\
\hline Equus ferus & 5 & 13 & 15 & 9 & 15 \\
\hline Cervus elaphus & 20 & 9 & 36 & 9 & 16 \\
\hline Capreolus capreolus & 0 & 1 & 0 & 0 & 0 \\
\hline Capra ibex & 17 & 20 & 7 & 3 & 6 \\
\hline Rupicapra rupricapra & 0 & 4 & 0 & 0 & 0 \\
\hline \multicolumn{6}{|l|}{ By Size Class } \\
\hline Large & 63.4 & 64.1 & 56.6 & 84.7 & 52.0 \\
\hline Medium & 36.6 & 30.4 & 43.4 & 15.1 & 15.1 \\
\hline Small & 0.0 & 5.5 & 0.0 & 0.3 & 0.3 \\
\hline
\end{tabular}

sampling biases, rather than a clear difference in subsistence strategy between two hominin species.

As a whole, although ibex is well represented in terms of NISP in both cultural assemblages, large mammals clearly played the most important role in the diet during both Mousterian and Aurignacian occupations in Šalitrena Pećina. Both Neanderthals and modern humans intensively exploited the fluvial plain biotopes, located less than 1.5 hours' walking distance from the site. In addition, the presence of ibex reflects the exploitation of mountain environments by both human species (Figures 6a and 7).

The presence of beaver during Mousterian could be related to a natural death, given the proximity of the cave mouth to the Ribnica River, as the remains do not show evidence of human modification.

Finally, although the macromammals recovered at the site are not very sensitive to climatic change because of their plasticity vis-à-vis warmer and colder environments, the spectrum of ungulates is typical of both forested and grassland habitats, which is in agreement with the modelled temperatures and the paleoenvironmental reconstructions of the MIS3 in eastern Europe. In fact, climatic simulations of Greenland Stadial $12(-46 \mathrm{ka}$ cal bp) with a regional climatic model (RCA-3) coupled with a dynamic vegetation-terrestrial ecosystem model (LPJ-GUESS) show that the region was then dominated by semi-open areas, with a tree cover of ca. 50-60\% (Kjellström et al. 2010) (Figure 6b). 


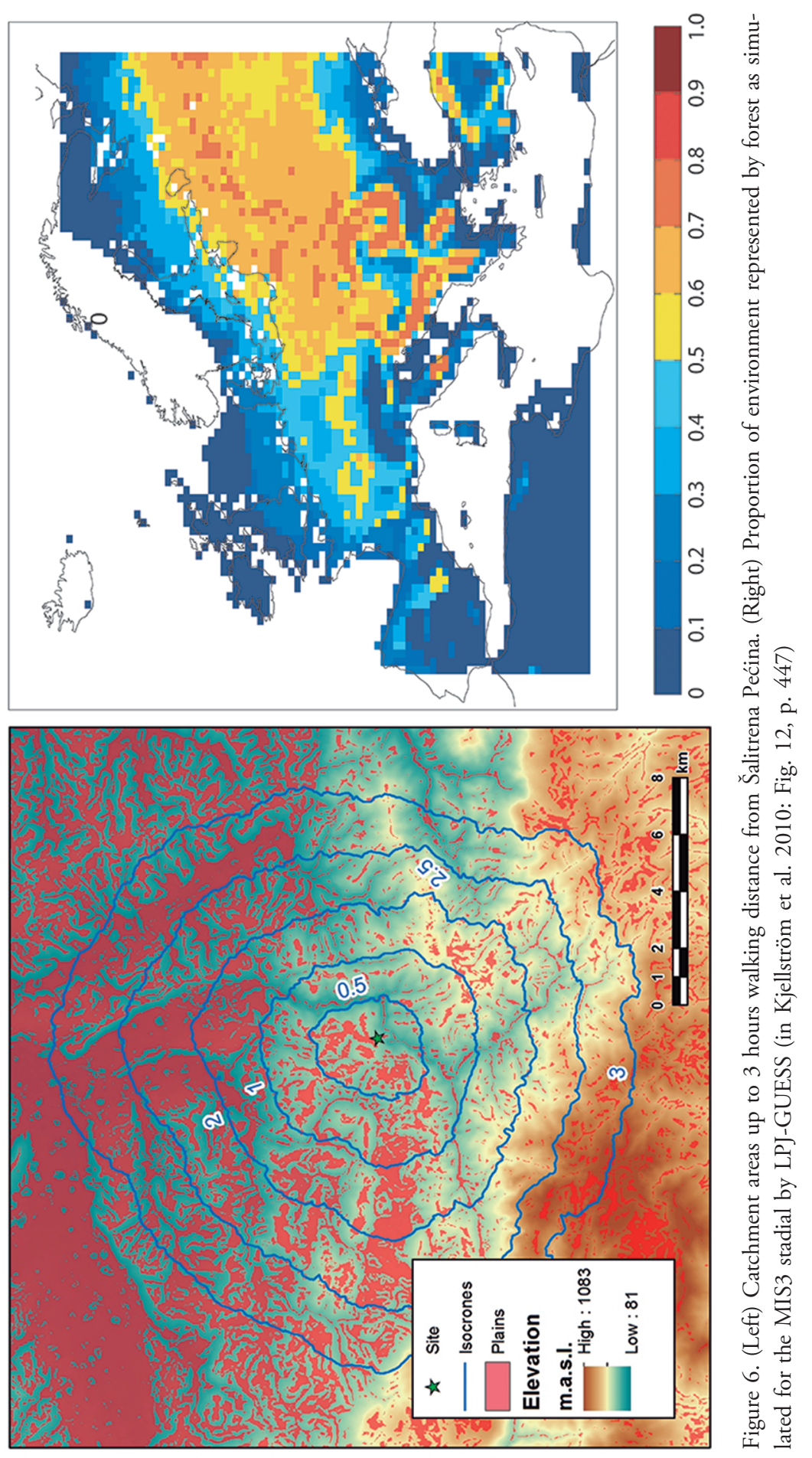




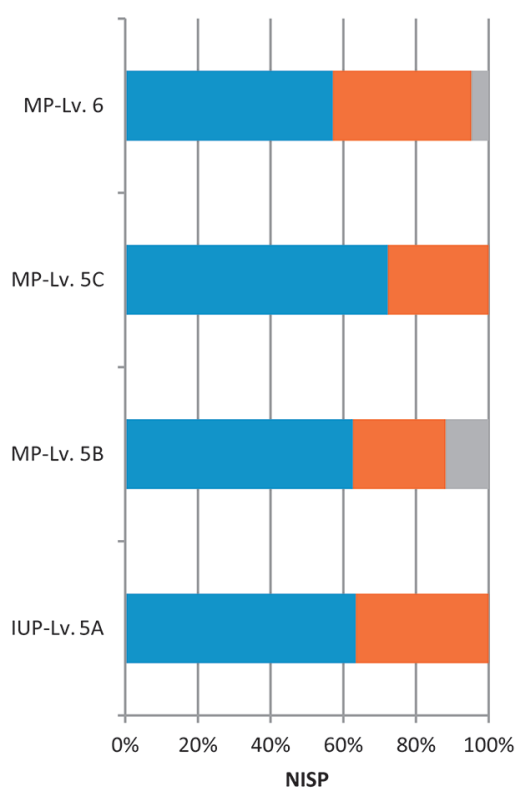

Large-size Medium-size $\square$ Small-size

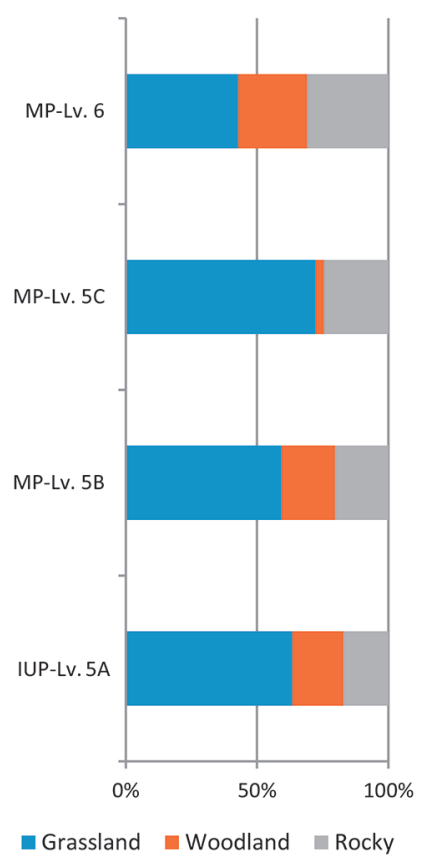

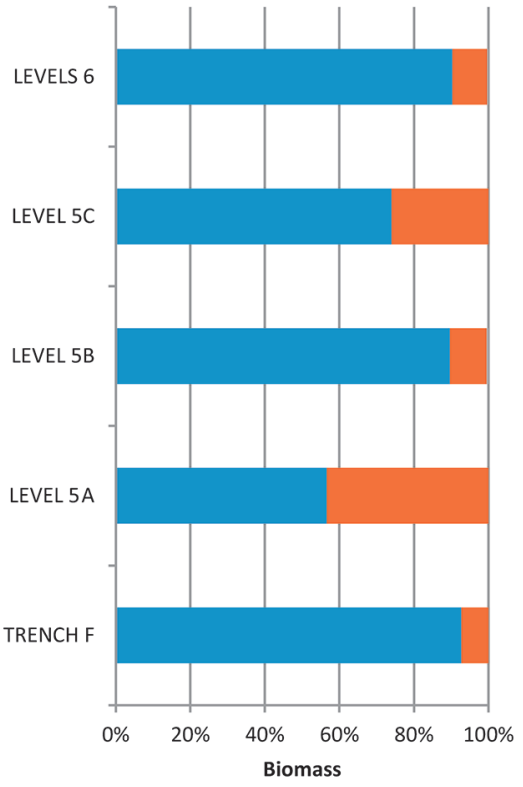

Large-size Medium-size $\quad$ Small-size

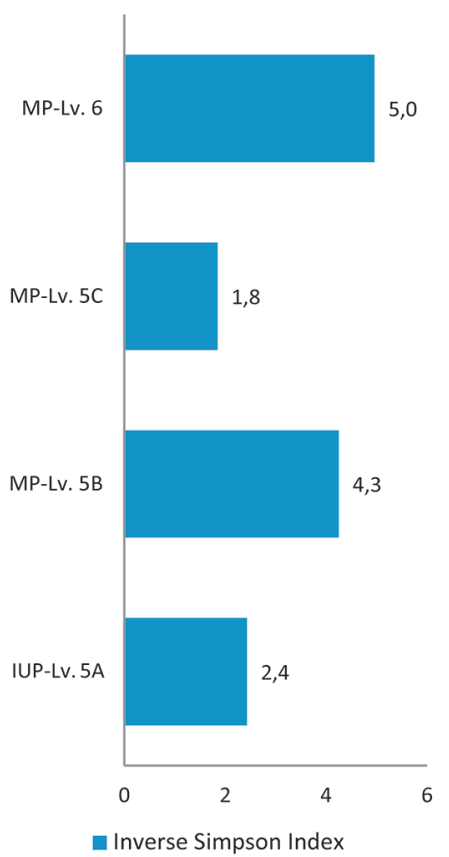

Figure 7. Diet comparison in terms of NISP and biomass for large, medium-size, and small ungulates in relation to habitat biotopes and inverse Simpson Index in Šalitrena Pećina. MP: Middle Palaeolithic, IUP: Initial Upper Palaeolithic. 


\section{Ungulate Mortality Profiles and Seasonality}

In general, the percentage of juvenile, prime-age, and older individuals in both the Mousterian and Aurignacian assemblages is consistent with live herd profiles. In both periods, there is a clear predominance of prime-age individuals. Specifically, in Mousterian level 5 c, only prime-age individuals were selected (Figure 8 ). The differences in the representation of juvenile and older individuals could reflect different activities at the site, the local population densities of the respective animals, or the site's location via-à-vis the herds at different times. Seasonality was difficult to assess, owing to the small sample sizes, although hints of an autumn occupation are present in Aurignacian level 5a.

\section{Mobility Patterns}

The relationship between human groups and the territory they inhabited is crucial for identifying mobility patterns (Marín-Arroyo 2013) and assessing whether they exploited available resources in an efficient way (Lupo 2006), thereby enhancing their chances for survival (Kaplan and Hill 1992). Topographic characterization of nearby

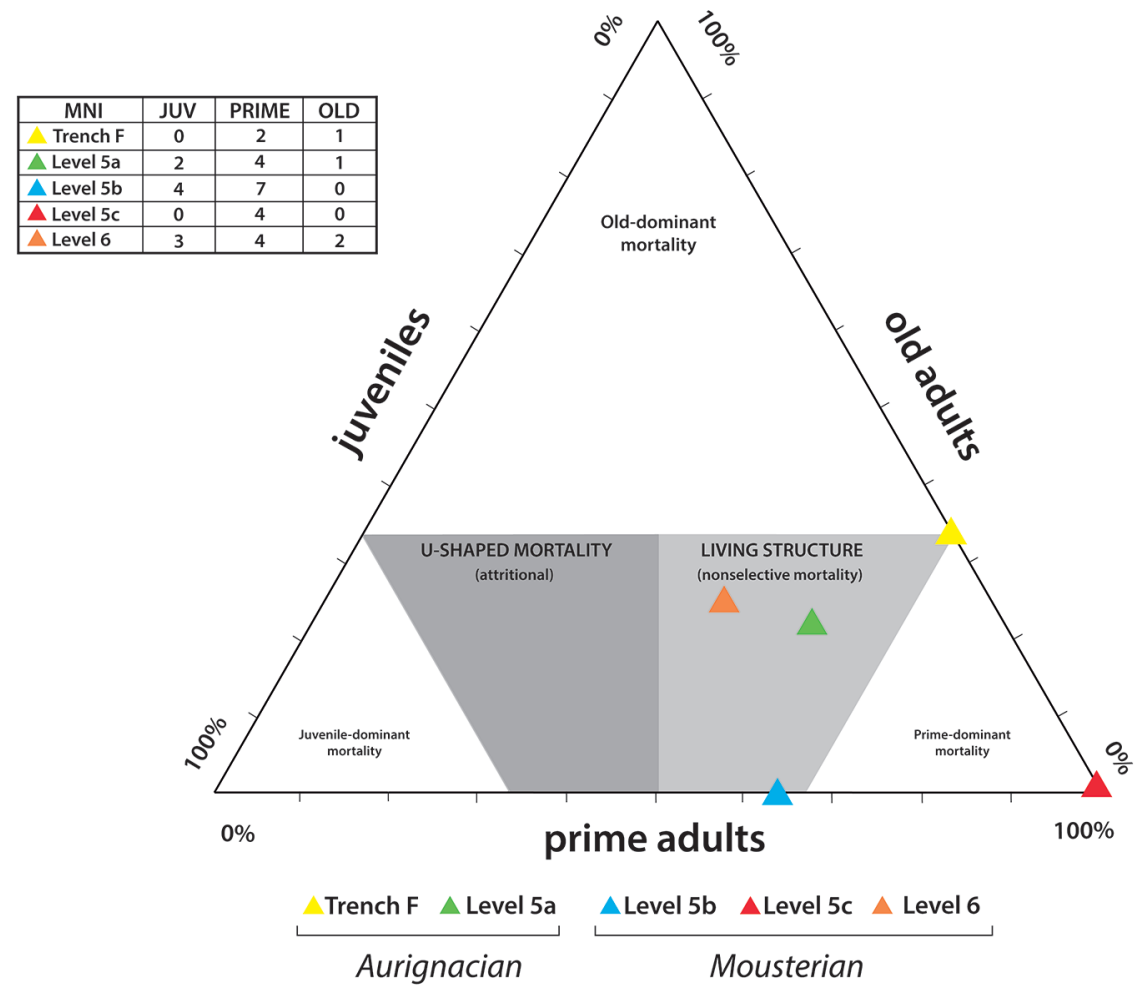

Figure 8. Mortality profiles of ungulates at Šalitrena Pećina during the Aurignacian and Mousterian. 
Table 8. Occurrence $\left(\mathrm{km}^{2}\right)$ and ratio of plains and hilly environments within easy walking distance of Šalitrena Pećina

\begin{tabular}{lccc}
\hline Travel time $(\mathrm{h})$ & Plains $\left(\mathrm{km}^{2}\right)$ & Hills $\left(\mathrm{km}^{2}\right)$ & Ratio Plains:Hills \\
\hline 0.5 & 2.9 & 7.7 & 0.37 \\
1 & 11.9 & 31.6 & 0.38 \\
1.5 & 31.7 & 72.4 & 0.44 \\
2 & 62.0 & 130.0 & 0.48 \\
2.5 & 104.9 & 202.3 & 0.52 \\
3 & 163.2 & 290.3 & 0.56 \\
\hline
\end{tabular}

catchment areas in comparison with the type of animals consumed is especially useful (Marín-Arroyo 2010). Figure 6a shows the catchment areas corresponding to different travel times around Šalitrena Pećina. The surface areas of plains and montane biotopes, as identified by a $10 \%$ slope threshold, is presented in Table 8 . Figure 6a shows the catchment areas up to 3 hours' walking distance from Šalitrena Pećina.

Access to the plains increases after a 1.5-hour walk from the site, meaning that both human populations had to travel that far to exploit the large and medium-sized mammals that inhabit the grasslands and woodlands and that dominate the hominin diets. This energetic expenditure should be reflected in the differential transport of skeletal remains if an optimal strategy was followed. Table 9 presents the results of the bivariate correlations between \%MAU and both MGUI and bone density, showing that there is no significant correlation with the utility index. On the contrary, the

Table 9. Correlations between \%MAU and both MGUI and bone density ( $\rho_{s}$ is significant if $p<0.05$ ). Positive and significant correlations are shaded.

\begin{tabular}{|c|c|c|c|c|c|c|c|}
\hline & \multirow[b]{3}{*}{ Level } & \multicolumn{6}{|c|}{ Mammal Size Class } \\
\hline & & \multicolumn{2}{|c|}{ Large } & \multicolumn{2}{|c|}{ Medium } & \multicolumn{2}{|c|}{ Small } \\
\hline & & $\rho_{\mathrm{s}}$ & $p$ & $\rho_{\mathrm{s}}$ & $p$ & $\rho_{\mathrm{s}}$ & $p$ \\
\hline \multicolumn{8}{|l|}{ \%MAU-MGUI } \\
\hline Aurignacian & $5 \mathrm{a}$ & 0.344 & 0.116 & 0.010 & 0.963 & 0.102 & 0.650 \\
\hline \multirow[t]{3}{*}{ Mousterian } & $5 b$ & 0.126 & 0.577 & 0.205 & 0.359 & 0.170 & 0.450 \\
\hline & $5 c$ & 0.160 & 0.477 & 0.011 & 0.961 & 0.249 & 0.264 \\
\hline & 6 & 0.095 & 0.674 & 0.382 & 0.080 & -0.193 & 0.390 \\
\hline \multicolumn{8}{|c|}{ \%MAU-Bone density } \\
\hline Aurignacian & $5 \mathrm{a}$ & 0.735 & 0.000 & 0.448 & 0.042 & 0.038 & 0.869 \\
\hline \multirow[t]{3}{*}{ Mousterian } & $5 b$ & 0.591 & 0.005 & 0.669 & 0.001 & 0.047 & 0.838 \\
\hline & $5 c$ & 0.569 & 0.007 & 0.617 & 0.003 & -0.148 & 0.523 \\
\hline & 6 & 0.656 & 0.001 & 0.643 & 0.002 & -0.046 & 0.842 \\
\hline
\end{tabular}




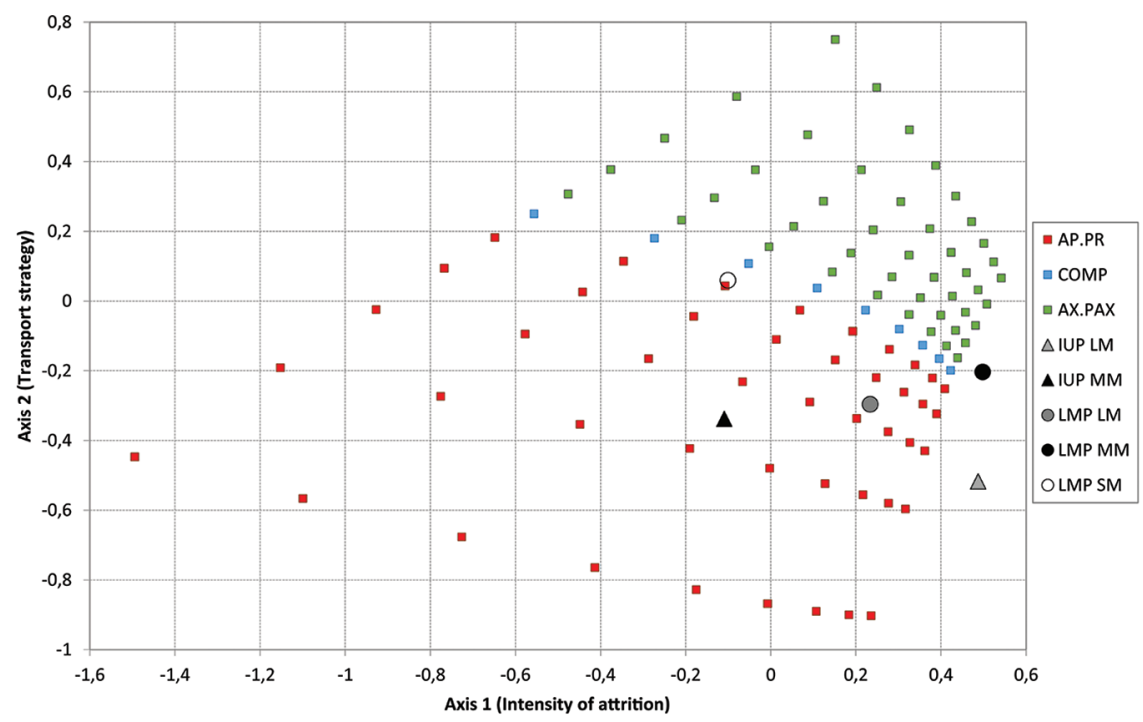

Figure 9. Correspondence analysis between recorded and theoretical skeletal profiles for large (LM) and medium-size (MM) mammals in Šalitrena Pećina during the Late Middle Palaeolithic (LMP) and the Initial Upper Palaeolithic (IUP). Axis 1 accounts for the degree of attrition, with larger numbers representing greater attrition. Axis 2 accounts for the transport strategy, with smaller numbers indicating more appendicular processing at the kill site. PAP: appendicular processing at the kill site, COMP: complete transport of the carcass, PAX: axial processing at the kill site.

role played by attrition in the deposit is quite notable, a fact that led to a skewing of the original anatomical representation of the skeletons, complicating inferences as to hypothesized human subsistence behavior. Outcomes related to small mammals are inconclusive because of the limited sample available for analysis.

In Figure 9, the transport strategy presumably carried out by each human species is explored by comparing the existing anatomical element representations with the outcomes from different theoretical strategies and potential degrees of attrition. During the Aurignacian, a greater degree of appendicular skeleton processing of large and medium-sized mammals took place at the kill sites, in addition to greater levels of attrition. During the Mousterian, medium-sized mammals were being brought to the site almost complete, whereas large mammals might have been processed at the kill site, as in the Aurignacian. Neanderthals might have processed the appendicular skeleton of larger prey at the kill site, but perhaps to a lesser extent in comparison with modern humans' butchering strategy.

\section{DISCUSSION}

Despite the rapid climatic oscillations during the MIS3, the central area of the Balkan Peninsula may have acted as a relatively short-term refugium for Neanderthals to 
withdraw after the arrival of AMH into Europe. The particular ecological conditions, with short river valleys and steep mountain areas with karstic caves and rockshelters, might have favored their retreat into this area south of the Danube River. For Serbia, the first chronometric dates for late Neanderthal and early AMH occupations are presented in this paper (Table 1). On the one hand, the late Middle Paleolithic dates of Šalitrena Pećina, ranging between 42 and $39 \mathrm{ka} \mathrm{cal} \mathrm{bp}$, are in agreement with the current modelled age for the end of the European Mousterian (Higham et al. 2014). Thus, evidence at Šalitrena Pećina would support late Neanderthal survival in southern European latitudes. In the southeast, they could have been forced to move south of the Danube, toward the mountainous part of the Balkan Peninsula. On the other hand, the Aurignacian dates at Šalitrena Pećina are relatively recent in comparison with the first dates of the presumed arrival of AMH into the continent (Douka et al. 2012; Szmidt et al. 2010), but they are significant to help unravel the activities of both populations in the region. In summary, our results show a chronological succession of Mousterian and Aurignacian occupations in this cave. No evidence of transitional industries between late Mousterian and Early Upper Paleolithic culture is found in Šalitrena Pećina. The hiatus between cultural complexes of ca. 7,000 years, previously suggested by Mihailović (2009), seems to indicate that Neanderthal and AMH groups did not coexist and interact in this particular region.

Our poor knowledge of the Middle to Upper Paleolithic transition in the central Balkans, because of the scarcity of sites, the lack of well-dated archaeological sites, and the absence of zooarchaeological and taphonomic studies, highlights the relevance of the data obtained at Šalitrena Pećina for understanding this complex transition between Neanderthal and early AMH in the Balkan region. Consequently, despite the small size of the faunal assemblages, the zooarchaeological results obtained in this study are meaningful as they provide the first data about the subsistence strategies and ecological niche exploitation of both late Neanderthal and early modern human populations in Serbia. Results indicate that both human species exploited the same ecosystems and hunted the same prey with only slight differences in the representation of each taxon, as is evidenced in other European regions (Boyle 2000; Grayson and Delpech 1998; Patou-Mathis 2000). Bovines are the most common taxa within the Neanderthal diet, followed by other large and medium-sized mammals (although those were supplementary), whereas modern humans exploited bovines as well as red deer, with very similar percentages of biomass. Although there is no clear evidence of a narrower diet breadth during the Aurignacian, Neanderthals did target a wider range of prey, including some low-ranked ones, such as chamois and roe deer, which are unrepresented in the Aurignacian levels. The representation of these smaller mammals could be interpreted as a more opportunistic pattern (Bar-Yosef 2004). Diversification at the end of the Middle Paleolithic has been attributed either to demographic pressure (Stiner et al. 1999) or to less productive hunting (Hortolà and Martínez-Navarro 2013), but in Šalitrena Pećina diversification is debatable since the percentage of small prey is relatively low. In addition, there are no significant shifts in mortality profiles 
during the Middle to Upper Paleolithic transition, whereas mortality data for ungulates suggest that adults were preferentially selected. These different taxonomic and age profiles could be a result of several factors, such as group size and functionality, animal population density, seasonality and settlement organization, among others, rather than by intentional choice of different subsistence strategies. Therefore, it is difficult to specify whether cognitive, technological, or social abilities could best explain these differences.

Regarding anatomical element representation, Neanderthals brought whole carcasses of medium-sized mammals back to the site, whereas modern humans processed the same prey more intensively at the kill sites and brought back to the cave mostly appendicular elements. The topographic location of Šalitrena Pećina, surrounded by extensive fluvial plains that provided the bulk of the diet in both periods, is key to understanding the potential energetic yield that each human species managed to reach. The fact that $\mathrm{AMH}$ practiced a more intensive processing of the appendicular skeleton at the kill site could be a reflection of larger catchment areas (Lupo 2006; Marín-Arroyo 2013; O'Connell et al. 1988; Rabinovich and Hovers 2004), perhaps due to lower animal density resulting from climatic instability. This processing behavior may have been a response to a need to maximize the energetic contribution to the camp, due to either a larger population to sustain or lower resource availability. Whereas Neanderthals might have had greater energetic needs (De Groote 2011), AMH would have possessed lower basal energetic costs because of their smaller body size and more efficient locomotion owing to their longer lower limbs (MacDonald et al. 2009; SteudelNumbers and Tilkens 2004; Weaver and Steudel-Numbers 2005). These physiological features might explain some of the strategies they adopted, although the small size of the archaeofaunal sample precludes drawing definitive conclusions. The lack of a seasonal signal in the timing of hunting events might emphasize the great flexibility in Middle Paleolithic subsistence (Boyle 2000; Gaudzinski and Niven 2009; Grayson and Delpech 2006; Morin 2004). Nevertheless, Neanderthal hunting efficiency, as measured by time and effort expended to kill their prey, may have been lower than that of early modern humans in Europe and in Africa (Marean 2005; Villa and Roebroeks 2014).

There is not yet enough evidence, at least in this particular region, to attribute Neanderthal extinction to subsistence issues. The differences observed in the Šalitrena Pećina faunal assemblages are not large enough to identify nutritional stress from lower carrying capacity or climatic instability. The representation of ungulates and the anthropogenic marks on the bones do not reflect a climatic change either, unlike in Roc de Marsal and Pech de l'Azé IV, where Neanderthals were processing faunal remains more heavily during glacial periods as a response to increased nutritional stress (Hodgkins et al. 2016). In summary, despite the intense current fieldwork and analyses to find Paleolithic human occupations and to provide information about the behavior of both human species during the Middle and Upper Paleolithic, more multidisciplinary studies such as micromorphology, micromammals, pollen, and stable isotope analyses are needed not only for Šalitrena Pećina, but also throughout Serbia and the Balkans. 


\section{CONCLUSION}

The late Mousterian occupations of Šalitrena Pećina, located in the central Balkans, a likely mountainous refugium for Neanderthals during the rapid dispersal of Anatomically Modern Humans throughout Europe along the Danube corridor, fills an important gap in the study of the Middle to Upper Paleolithic transition in the southeastern part of Europe. The zooarchaeological analysis of the admittedly small faunal assemblages has allowed us to begin to reconstruct the subsistence strategies carried out by both human species in Serbia. Despite the climatic fluctuations during MIS3, the differences in subsistence between Neanderthals and AMH are narrow, as they were exploiting the same habitats and prey. Future research should focus on discovering contemporaneous sites where human remains might be found, investigating the role of other dietary resources, and reconstructing the climatic and environmental conditions at that time. All these data will help us to understand human behavior during Late Pleistocene in Serbia, and in the Balkans in general.

\section{NOTE}

Thanks are due to P. Miracle for introducing the first author to the Balkans Paleolithic and especially to Prof. R. Foley and M. Lahr for their support during the initial part of this research at the University of Cambridge. The authors want to acknowledge the National Museum in Belgrade and the Natural History Museum in London for the facilities provided during the study of Šalitrena Pećina material. V. Dimitrević kindly welcomed ABMA to her Laboratory of Bioarchaeology at the University of Belgrade. ABMA warmly appreciates the significant help of M. Lopicić and S. Milosević during her research stays in Belgrade. Thanks to K. Douka for the shell pretreatment, J. Jones and the JAR editor for English language correction, and L. Agudo for her technical support with some of the figures. This revised version of the paper profited from the criticism and advice of three anonymous reviewers and especially the editor, L. G. Straus. ABMA has a contract with the Ramón y Cajal Research Program (RYC2011-00695) and wants to thank D. Ocio for his constant support. This research has been supported by a British Academy PDF (2011) and a Small Research Grant (SG102618) and by funds from the McDonald Institute for Archaeological Research in Cambridge during 2010/11. Currently, the research is involved in projects funded by the European Commission through FP7-PEOPLE-2012-CIG (Ref.N 322112) and by the Spanish Ministry of Economy and Competitiveness (HAR2012-33956). Since 2004, excavation in Šalitrena Pećina has been financed by the Ministry of Culture and Information of the Republic of Serbia.

\section{REFERENCES CITED}

Banks, W. E., F. d'Errico, A. T. Peterson, M. Kageyama, A. Sima, and M. F. Sánchez-Goñi. 2008. Neanderthal extinction by competitive exclusion. PLoS One 3(12):3972.

Bar-Yosef, O. 2004. Eat what is there: Hunting and gathering in the world of Neanderthals and their neighbours. International Journal of Osteoarchaeology 14(3-4): 333-42. 
Basler, D., ed. 1975. Crvena Stijena: Zbornik radova. Nikšić: Zajednica Kulturnih Ustanova. Behrensmeyer, A. K. 1978. Taphonomic and ecological information from bone weathering. Paleobiology 4:150-62.

Binford, L.R. 1978. Nunamiut ethnoarchaeology. New York: Academic Press. 1981. Bones: Ancient men and modern myths. New York: Academia Press.

Blumenschine, R. J. 1995. Percussion marks, tooth marks, and the experimental determinations of the timing of hominid and carnivore access to long bones at FLK Zinjanthropus, Olduvai Gorge, Tanzania. Journal of Human Evolution 29:21-51.

Bocherens, H., and D. Drucker. 2006. "Dietary competition between Neanderthals and modern humans: Insights from stable isotopes," in When Neanderthals and modern humans met. Edited by N. Conard, pp. 129-43. Tübingen: Kerns Verlag.

Borić, D., V. Dimitrijević, D. White, C. Lane, C. French, and E. Cristiani. 2012. Early modern human settling of the Danube corridor: The Middle to Upper Palaeolithic site of Tabula Traiana Cave in the Danube Gorges (Serbia). Antiquity 86(334). Available at http:// antiquity.ac.uk/projgall/boric334/

Boyle, K. V. 2000. Reconstructing Middle Palaeolithic subsistence strategies in the South of France. International Journal of Osteoarchaeology 10:336-56.

Bronk Ramsey, C. 2009. Bayesian analysis of radiocarbon dates. Radiocarbon 51:337-60.

Bronk Ramsey, C., T. F. G. Higham, A, Bowles, and R. Hedges. 2004. Improvements to the pretreatment of bone at Oxford. Radiocarbon 46(1):155-63.

Bunn, H. T. 1981. Archaeological evidence for meat-eating by Plio-Pleistocene hominids from Koobi Fora and Olduvai Gorge. Nature 291:574-77.

Cannon, M. D. 2003. A model of central place forager prey choice and an application to faunal remains from the Mimbres Valley, New Mexico. Journal of Anthropolological Archaeolology 22:1-25.

Capaldo, S. D. 1998. Simulating the formation of dual patterned archaeofaunal assemblages with experimental control samples. Journal of Archaeological Science 25:311-30.

Capaldo, S. D., and R. J. Blumenshine. 1994. A quantitative diagnosis of notches made by hammerstone percussion and carnivore gnawing on bovid long bones. American Antiquity 59:724-48.

Conard, N. J. 2002. "The timing of cultural innovations and the dispersal of modern humans in Europe," in Proceedings of the DEUQUA-Meeting August 26-28, 2002, Potsdam, Germany. Edited by A. Brauer, J. F. W. Negendank, and M. Bohm, pp. 82-94. Terra Nostra 2002/6. Oxford.

Conard N. J., and M. Bolus. 2003. Radiocarbon dating the appearance of modern humans and timing of cultural innovations in Europe: New results and new challenges. Journal of Human Evolution 44:331-71.

Cvetković, N., and V. Dimitrijević. 2014. Cave bears (Carnivora, Ursidae) from the Middle and Late Pleistocene of Serbia: A revision. Quaternary International 339-340:197-208

De Groote, I. 2011. The Neanderthal lower arm. Journal of Human Evolution 61:396-410.

Dimitrijević, V. 1997. Upper Pleistocene mammals from cave deposits of Serbia. Geoloski Anali Balkanskog Poluostrva 61(2):179-370.

Dimitrijević, V., I. Dulić, and N. Cvetković. 2014. The Janda cavity at Fruska Gora: The first cave assemblage from the southeast Pannonian lowland (Vojvodina, Serbia). Quaternary International 339-340:97-111. 
Dogandžić, T., S. McPherron, and D. Mihailović. 2014. "Middle and Upper Paleolithic in the Balkans: Continuities and discontinuities of human occupations," in Palaeolithic and Mesolithic research in the central Balkans. Edited by D. Mihailović, pp. 81-94. Belgrade: Serbian Archaeological Society.

Domínguez-Rodrigo, M. 1997. Meat-eating by early hominids at the FLK 22 Zinjanthropus site, Olduvai Gorge (Tanzania): An experimental approach using cut-mark data. Journal of Human Evolution 33:669-90.

Domínguez-Rodrigo, M., and R. Barba. 2005. A study of cut marks on small-sized carcasses and its application to the study of cut-marked bones from small mammals at the FLK Zinj site. Journal of Taphonomy 3:121-34.

Douka, K., R. E. M. Hedges, and T. F. G. Higham. 2010. Improved AMS 14C dating of shell carbonates using high-precision X-Ray Diffraction (XRD) and a novel density separation protocol (CarDS). Radiocarbon 52:735-51.

Douka, K., S. Grimaldi, G. Boschian, A. del Lucchese, and T. F. G. Higham. 2012. A new chronostratigraphic framework for the Upper Palaeolithic of Riparo Mochi (Italy). Journal of Human Evolution 62:286-99.

Douka, K., T. Higham, R. Wood, P. Boscato, P. Gambassini, P. Karkanas, M. Peresani, and A. Ronchitelli. 2014. On the chronology of the Uluzzian. Journal of Human Evolution 68:1-13.

Finlayson, C. 2004. Neanderthals and modern humans: An ecological and evolutionary perspective. Cambridge: Cambridge University Press.

2009. The humans who went extinct: Why Neanderthals died out and we survived. Oxford: Oxford University Press.

Fisher J. W. 1995. Bone surface modifications in zooarchaeology. Journal of Archaeological Method and Theory 2:7-68.

Flores J. 1998. A mathematical model for the Neanderthal extinction. Journal of Theoretical Biology 191:295-98.

Gaudzinski, S., and L. Niven. 2009. "Hominin subsistence patterns during the Middle and Late Paleolithic in northwestern Europe," in The evolution of hominin diets: Integrating approaches to the study of Palaeolithic subsistence. Edited by J.-J. Hublin and M. P. Richards, pp. 99-111. Dordrecht: Springer Science

Grayson, D. K., and F. Delpech. 1998. Changing diet breadth in the early Upper Paleolithic of southwestern France. Journal of Archaeological Science 25:1119-30.

- 2006. "Was there increasing diet specialization across the Middle-to-Upper Paleolithic transition in France?" in When Neanderthals and modern humans met. Edited by N. J. Conard, pp. 377-417. Tübingen: Kerns Verlag.

Green, R. E., J. Krause, A. W. Briggs, et al. 2010. A draft sequence of the Neandertal genome. Science 328:710-22.

Griffiths, H. I., B. Krystefek, and J. M. Reed, eds. 2004. Balkan biodiversity: Pattern and process in the European hotspot. Dordrecht: Kluwer Academic.

Higham, T., R. M. Jacobi, and C. Bronk Ramsey 2006a. AMS radiocarbon dating of ancient bone using ultrafiltration. Radiocarbon 48:179-95.

Higham, T., C. Bronk Ramsey, I. Karavanic, F. H. Smith, and E. Trinkaus. 2006b. Revised direct radiocarbon dating of the Vindija G1 Upper Paleolithic Neandertals. Proceedings of the National Academy of Sciences (USA) 103(3):553-57. 
Higham, T., T. Compton, C. Stringer, R. Jacobi, B. Shapiro, et al. 2011. The earliest evidence for anatomically modern humans in northwestern Europe. Nature 479:521-24.

Higham, T. F. G., L. Basell, R. M. Jacobi, R. Wood, C. Bronk Ramsey, and N. J. Conard. 2012. Testing models for the beginnings of the Aurignacian and the advent of figurative art and music: The radiocarbon chronology of Geißenklösterle. Journal of Human Evolution 62:664-76.

Higham, T. F. G., K. Douka, R. Wood, C. Bronk Ramsey, and F. Brock, et al. 2014. The timing and spatio-temporal patterning of Neanderthal disappearance. Nature 512:306-9.

Hockett, B., and J. Haws. 2003. Nutritional ecology and diachronic trends in Paleolithic diet and health. Evolutionary Anthropology 12(5):211-16.

Hodgkins, J., C. Marean, A. Turq, D. Sandgathe, S. McPherron, and H. Dibble. 2016. Climate-mediated shifts in Neandertal subsistence behaviors at Pech de l'Azé IV and Roc de Marsal (Dordogne Valley, France). Journal of Human Evolution 96:1-18.

Holechek, J. L., R. D. Pieper, and C. H. Herbel. 1998. Range management principles and practices, third ed. Upper Saddle River, NJ: Prentice-Hall.

Hortolà, P., and B. Martínez-Navarro. 2013. The Quaternary megafaunal extinction and the fate of Neanderthals: An integrative working hypothesis. Quaternary International 295:69-72.

Hublin, J. J. 2015. The modern human colonization of western Eurasia: When and where? Quaternary Science Reviews 118:194-210.

Jez, Z., and Z. Kaluderovic. 1985. Šalitrena Pećina: Paleolitsko i neolitsko nalaziste. Arheoloski Pregled 25:33-34.

Kaplan, H., and K. Hill. 1992. "The evolutionary ecology of food acquisition," in Evolutionary ecology and human behavior. Edited by E. A. Smith and B. Winterhalder, pp 167-201. New York: Aldine.

Kjellström, E., J. Brandefelt, J.-O. Näslund, B. Smith, G. Strandberg, A. H. L. Voelker, and B. Wohlfarth. 2010. Simulated climate conditions in Europe during the Marine Isotope Stage 3 stadial. Boreas 39:436-56.

Kozlowski, J. K. 1998. "The Middle and Early Upper Paleolithic around the Black Sea," in Neanderthals and modern humans in Western Asia. Edited by T. Akazawa, K. Aoki, and O. Bar-Yosef, pp. 461-82. New York: Plenum Press.

- 2006. Early human migrations: Incipient stages of Old World peopling. Diogenes 211:9-22.

Lam, Y. M., X. Chen, and O. M. Pearson. 1999. Intertaxonomic variability in patterns of bone density and the differential representation of bovid, cervid, and equid elements in the archaeological record. American Antiquity 64:343-62.

Lupo, K. D. 2006. What explains the carcass field processing and transport decisions of contemporary hunter-gatherers? Measures of economic anatomy and zooarchaeological skeletal part representation. Journal of Archaeological Method and Theory 13(1):19-66.

Lupo, K. D., and J. F. O'Connell. 2002. Cut and tooth mark distributions on large animal bones: Ethnoarchaeological data from the Hadza and their implications for current ideas about early human carnivory. Journal of Archaeological Science 29:85-109.

Lyman, L. 1994. Vertebrate taphonomy. Cambridge: Cambridge University Press.

MacDonald, K., W. Roebroeks, and A. Verpoorte. 2009. "An energetics perspective on the Neanderthal record," in The evolution of hominin diets: Integrating approaches to the study 
of Palaeolithic subsistence. Edited by J. J. Hublin and M. P. Richards, pp. 211-20. New York: Springer Science.

Marean, C.W. 2005. "From the tropics to the colder climates: Contrasting faunal exploitation adaptations of modern humans and Neanderthals," in From tools to symbols: From early hominids to modern humans. Edited by F. d'Errico and L. Backwell, pp. 333-71. Johannesburg: Witwatersrand University Press.

Marean, C. W., Y. Abe, C. J. Frey, and R. C. Randal. 2000. Zooarchaeological and taphonomic analysis of the Die Kelders Cave 1 layers 10 and 11 Middle Stone Age larger mammal fauna. Journal of Human Evolution 38:197-233.

Marín-Arroyo, A. B. 2009a. The use of Optimal Foraging Theory to estimate Late Glacial site catchment areas from a central place: The case of eastern Cantabria, Spain. Journal of Anthropological Archaeology 28:27-36.

- 2009b. A comparative study of analytic techniques for skeletal part profile interpretation at El Mirón Cave (Cantabria, Spain). Archaeofauna 18:79-98.

- 2010. Arqueozoología en el cantábrico oriental durante la transición Pleistoceno/ Holoceno: La Cueva del Mirón. Publican, Universidad de Cantabria. Santander.

2013. Palaeolithic human subsistence in Mount Carmel (Israel). A taphonomic assessment of Middle and Early Upper Palaeolithic faunal remains from Tabun, Skhul and el-Wad. International Journal of Osteoarchaeology 23(3):254-73.

Marín-Arroyo, A.B., and M. R. González Morales. 2009. Comportamiento económico de los últimos cazadores-recolectores y primeras evidencias de domesticación en el occidente de Asturias. La Cueva de Mazaculos II. Trabajos de Prehistoria 66(1):47-74.

Marín-Arroyo, A. B., D. Landete, G. Vidal, R. Seva, M. González Morales, and L. G. Straus. 2008. Archaeological implications of human-derived manganese coatings: A study of blackened bones in El Mirón Cave, Cantabrian Spain. Journal of Archaeological Science 35(3): 801-13.

Marín-Arroyo, A. B., M. D. Landete Ruiz R. Seva Román, and M. Lewis. 2014. Manganese coating of the Tabun faunal assemblage: Implications for modern human behaviour in the Levantine Middle Palaeolithic. Quaternary International 330:10-18.

Mellars, P. 1991. Cognitive changes and the emergence of modern humans in Europe. Cambridge Archaeological Journal 1(1):63-76.

—. 2011. The earliest modern humans in Europe. Nature 479:483-85.

Mellars, P., and J. C. French. 2011. Tenfold population increase in Western Europe at the Neandertal-to-Modern Human transition. Science 333:623-27.

Mihailović, B. 2008. "The Gravettian site Šalitrena Pećina near Mionica (western Serbia)," in The Palaeolithic of the Balkans. Edited by A. Darlas and D. Mihailović, pp. 101-6. BAR International Series 1819, Oxford: Archaeopress.

—. 2013. "Šalitrena pećina," in Rezultati novih arheoloških istraživanja u severozapadnoj Srbiji i susednim teritorijama. Edited by V. Filipović, R. Arsić, and D. Antonović, pp. 516. Beograd-Valjevo: SRP-SKO Arheološko Društvo, Zavod za Aaštitu Spomenika Kulture Valjevo.

Mihailović, B., D. Mihailović, A. Latas, and J. Lindal. 2014. "Šalitrena cave - terrace: Preliminary investigation results," in Palaeolithic and Mesolithic research in the central Balkans. Edited by D. Mihailović, pp. 77-82. Belgrade: Serbian Archaeological Society, 
Mihailović, D. 2008. "New data about the Middle Palaeolithic of Serbia," in The Palaeolithic of the Balkans. Edited by A. Darlas and D. Mihailović, pp. 93-100. BAR International Series 1819. Oxford: Archaeopress.

- 2009. Upper Palaeolithic and Mesolithic chipped stone industries from Crvena Stijena. Prehistoric settlements in caves and rock-shelters of Serbia and Montenegro, Fascicule II. Centar za Arheolos?ka Istraz?ivanja, University of Belgrade.

—, ed. 2014. Palaeolithic and Mesolithic research in the central Balkans. Belgrade: Serbian Archaeological Society.

Mihailović, D., and B. Mihailović. 2007. Considérations sur le Gravettien et l'épigravettien ancien des Balkans de l'ouest. Paleo 19:113-28.

2009. "Cultural regionalization in the Palaeolithic of the middle Danube basin and western Balkans," in Le concept de territoires dans le Paléolithique supérieur européen. Edited by F. Djindjan, J. Kozłowski, and N. Bicho, pp. 93-101. BAR International Series 1938. Oxford: Archaeopress.

Mihailović, D., B. Mihailović, and M. Lopičić. 2011. "The Palaeolithic in northern Serbia," in The Prehistory of Banat I - The Palaeolithic and Mesolithic. Edited by F. Drasovean, and B. Jovanović, pp. 77-101. Bucharest: Publishing House of the Romanian Academy.

Morin, E. 2004. Late Pleistocene population interaction in western Europe and modern origins: New insights based on the faunal remains from Saint-Césaire, southwestern France. PhD dissertation, University of Michigan.

Morley, M., and J. Woodward. 2011. The Campanian Ignimbrite (Y5) tephra at Crvena Stijena Rockshelter, Montenegro. Quaternary Research 75:683-96.

Müller, U. C., J. Pross, P. Tzedakis, C. Gamble, U. Kotthoff, G. Schmiedl, S. Wulf, and K. Christanis. 2011. The role of climate in the spread of modern humans into Europe. Quaternary Science Reviews 30:273-79.

O'Connell, J. F., K. Hawkes, and N. Blurton Jones. 1988. Hadza hunting, butchering, and bone transport and their archaeological implications. Journal of Anthropological Research 44:113-61.

Patou-Mathis, M. 2000. Neanderthal subsistence behaviours in Europe. International Journal of Osteoarchaeology 10(5):379-95.

Pérez Ripoll, M. 1992. Marcas de carniceria, fracturas intenciona-das y mordeduras de carnıvoros en huesos prehistoricos del mediterráneo español. Alicante: Instituto de Cultura Juan Gil Albert (Coleccion Patrimonio 15).

Pettitt, P. B. 1999. Disappearing from the world: An archaeological perspective on Neanderthal extinction. Oxford Journal of Archaeology 18(3):217-40.

Pickering, T. R., and C. P. Egeland. 2006. Experimental patterns of hammerstone percussion damage on bones: Implications for inferences of carcass processing by humans. Journal of Archaeological Science 33:459-69.

Rabinovich, R., and E. Hovers. 2004. Faunal analysis from Amud Cave: Preliminary results and interpretations. International Journal of Osteoarchaeology 14:287-306.

Reimer, P. J., E. Bard, A. Bayliss, J. W. Beck, et al. 2013. IntCal13 and Marine13 radiocarbon age calibration curves 0-50,000 years cal BP. Radiocarbon 55(4).

Richards, M., and E. Trinkaus. 2009. Isotopic evidence for the diets of European Neanderthals and early modern humans. Proceedings of the National Academy of Sciences (USA) 106 (38):16034-39. 
Roebroeks, W. 2008. Time for the Middle to Upper Paleolithic transition in Europe. Journal of Human Evolution 55:918-26.

Rogers, A. R. 2000. Analysis of bone counts of maximum likelihood. Journal of Archaeological Science 27:111-25.

Roksandic, M., D. Mihailović, N. Mercier, V. Dimitrijević, et al. 2011. A human mandible (BH-1) from the Pleistocene deposits of Mala Balanica Cave (Sićevo Gorge, Niš, Serbia). Journal of Human Evolution 61(2):186-96.

Selvaggio, M. M. 1998. Evidence for a three-stage sequence of hominid and carnivore involvement with long bones at FLK Zinjanthropus, Olduvai Gorge, Tanzania. Journal of Archaeological Science 25:191-202.

Shea, J. J., and M. L. Sisk. 2010. Complex projectile technology and Homo sapiens dispersal from Africa to western Eurasia. Paleoanthropology 2010:100-22.

Shipman, P. 1981. Life history of a fossil: An introduction to taphonomy and paleoecology. Cambridge: Harvard University Press.

Soffer, O. 1994. "Ancestral lifeways in Eurasia: The Middle and Upper Paleolithic records," in Origins of anatomically modern humans. Edited by M. Nitecky and D. Nitecky, pp. 101-19. New York: Plenum Press.

Steudel-Numbers, K., and M. Tilkens. 2004. The effect of lower limb length on the energetic cost of locomotion: Implications for fossil hominids. Journal of Human Evolution 47:95109.

Stewart, J. R. 2004. Neanderthal and modern human competition? A comparison between the mammals associated with Middle and Upper Palaeolithic industries in Europe during OIS 3. International Journal of Osteoarchaeology 14:178-89.

2007. Neanderthal extinction as part of the faunal change in Europe during Oxygen Isotope Stage 3. Acta zoologica cracoviensia 50A(1-2):93-124.

Stiner, M. C. 1991. Food procurement and transport by human and non-human predators. Journal of Archaeological Science 18:455-82.

2005. The faunas of Hayonim Cave (Israel): A 200,000-year record of Paleolithic diet, demography and society. Cambridge: Peabody Museum Press, Harvard University.

Stiner, M. C., N. D. Munro, T. A. Surovell, E. Tchernov, and O. Bar-Yosef. 1999. Palaeolithic population growth pulses evidenced by small animal exploitation. Science 283(5399) 190-94.

Szmidt, C. C., C. Normand, G. S. Burr, G. W. L. Hodgins, and S. LaMotta. 2010. AMS 14C dating the Protoaurignacian/Early Aurignacian of Isturitz, France: Implications for Neanderthalmodern human interaction and the timing of technical and cultural innovations in Europe. Journal of Archaeological Science 37:758-68.

Tzedakis, P. C. 2004. "The Balkan as prime glacial refugial territory of European temperate trees," in Balkan biodiversity: Pattern and process in the European hotspot. Edited by H. I. Griffiths, B. Krystefek, and J. M. Reed, pp. 49-69. Dordrecht: Kluwer Academic.

Tzedakis, P. C., and K. D. Bennett. 1996. Interglacial vegetation succession: A view from southern Europe. Quaternary Science Reviews 14:967-82.

van Andel, T. H., W. Davies, and B. Weninger. 2003. "The human presence in Europe during the Last Glacial Period, I: Human migrations and the changing climate," in Neanderthals and modern humans in the European landscape during the last glaciation: Archaeological 
results of the Stage 3 Project. Edited by T. H. van Andel and W. Davies, pp. 31-52. Cambridge: McDonald Institute for Archaeological Research.

Villa, P., and E. Mahieu. 1991. Breakage patterns of human long bones. Journal of Human Evolution 20:1-22.

Villa, P., and W. Roebroeks. 2014. Neandertal demise: An archaeological analysis of the modern human superiority complex. PLoS One 9, e96424.

Weaver, T., and K. Steudel-Numbers. 2005. Does climate or mobility explain the differences in body proportions between Neanderthals and their Upper Palaeolithic successors? Evolutionary Anthropology 14:218-23.

Weiss, S., and N. Ferrand, eds. 2007. Phylogeography of southern European refugia. Dordrecht: Springer.

Wood, R. E., C. Barroso-Ruíz, M. Caparrós, J. Jordá Pardo, B. Galván Santos, and T. F. G. Higham. 2013. Radiocarbon dating casts doubt on the late chronology of the Middle to Upper Palaeolithic transition in southern Iberia. Proceedings of the National Academy of Sciences (USA) 110(8):2781-86.

Wood, R. E., A. Arrizabalaga, M. Camps, S. Fallon, et al. 2014. The chronology of the earliest Upper Palaeolithic in northern Iberia: New insights from L'Arbreda, Labeko Koba and La Viña. Journal of Human Evolution 69:91-109

Zilhão, J. 2006. Chronostratigraphy of the Middle-to-Upper Paleolithic transition in the Iberian Peninsula. Pyrenae 37:7-84.

Zubrow, E. B. W. 1989. "The demographic modelling of Neanderthal extinction," in The human revolution. Edited by P. Mellars and C. Stringer, pp. 212-31. Edinburgh: Edinburgh University Press. 